\title{
Development of Manufacturing Systems Models Using VRML
}

Kasthurirangan Krishnamurthy Michael J. Iuliano

Charles McLean

U.S. DEPARTMENT OF COMMERCE

Technology Administration

National Institute of Standards

and Technology

Gaithersburg, MD 20899-0001

QC 



\section{Development of Manufacturing Systems Models Using VRML}

\section{Kasthurirangan Krishnamurthy Michael J. Iuliano \\ Charles McLean}

U.S. DEPARTMENT OF COMMERCE

Technology Administration

National Institute of Standards

and Technology

Gaithersburg, MD 20899-0001

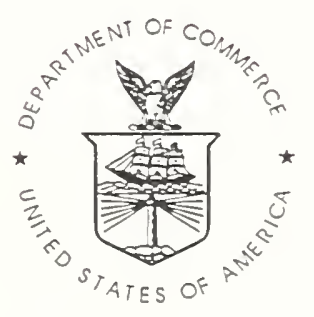

U.S. DEPARTMENT OF COMMERCE

William M. Daley, Secretary

TECHNOLOGY ADMINISTRATION

Gary R. Bachula, Acting Under Secretary for Technology

NATIONAL INSTITUTE OF STANDARDS

AND TECHNOLOGY

Raymond G. Kammer, Director 



\title{
Development of Manufacturing Systems Models Using VRML
}

\author{
Kasthurirangan Krishnamurthy ${ }^{1}$ \\ Michael J.Iuliano \\ Charles McLean \\ National Institute of Standards and Technology, \\ Gaithersburg, MD.
}

\begin{abstract}
The System Integration for Manufacturing Applications (SIMA) Program is a major internal effort being undertaken at the National Institute of Standards and Technology (NIST) to support the application of information technologies to the manufacturing domain. Within the SIMA Program, it is often necessary to convey the integration work underway to potential collaborators, sponsors, and supporters within industry, other government agencies, and academic institutions. The Technology Outreach Project was initiated to demonstrate the work underway and transfer technology in the various projects within the SIMA. This paper describes the application of Virtual Reality Modeling Language (VRML) technology to describe the various aspects of a virtual manufacturing scenario on the Internet. Using VRML, we created a unique multidimensional world in which the audience was able to fly through photos of conventional machine shop and a high volume assembly line producing consumer products, system architecture diagram, information system models and virtual manufacturing systems.
\end{abstract}

I Kasthurirangan Krishnamurthy is a Guest Researcher at NIST, from Virginia Polytechnic Institute and State University, Blacksburg, Virginia. 


\section{Background}

\subsection{NIST and SIMA}

The System Integration for Manufacturing Application (SIMA) Program (1) is an inter-laboratory effort at the National Institute of Standards and Technology (NIST). The program was started under the United States (U.S.) Government's High Performance Computing and Communications (HPCC) (2) Initiative. This program was created to address the issues related to the application of information technology solutions to manufacturing systems integration problems. Initiated in Fiscal Year'94 (FY94), the SIMA Program works with U.S. industry to:

- Develop information exchange and interface solutions to manufacturing integration problems,

- Establish test mechanisms for validating solutions and implementations, and

- Transfer information technology solutions to manufacturing enterprises.

These efforts will give manufacturing industries a mechanism for communicating product and process data among various manufacturing activities such as product/process design, analysis, planning, scheduling, production, and quality control. Manufacturing applications require standard protocols for data exchange (information interfaces) to communicate with each other via National Information Infrastructure (NII) technologies (3). The development of information interfaces between the communications infrastructure and manufacturing applications, between different manufacturing applications, and between these applications and their users will improve integration, and thereby usability, of these systems. 


\subsection{Motivation for the Project}

The SIMA Program encompasses twenty-seven projects across all of NIST's six laboratories (4). The projects are organized into three program elements: manufacturing systems, standards development, and testbeds/technology transfer. Within the SIMA Program, it is often necessary to convey the integration work underway to potential collaborators, sponsors and supporters within industry, other government agencies, and academic institutions. The main goal of this Technology Outreach project is to demonstrate the work underway in the various projects within the SIMA. Some of the main objectives include:

- Develop a virtual manufacturing demonstration, which can be used to illustrate the integration and standardization activities underway within the SIMA Manufacturing Systems Environment projects;

- Construct a multi-faceted model of a virtual manufacturing system to illustrate the different project activities, manufacturing systems, data, interface specifications, and, ultimately, standards required to integrate manufacturing design, planning and production systems in the future;

- Explain how industry could make use of Initial Manufacturing Exchange Specification (IMES) (5). IMES documents describe the phases required to develop the specification of an interface between software systems to be used in supporting a particular manufacturing activity or manufacturing scenario;

- Develop hyperlinks which tie proposed IMESs, Application Protocols (APs), and standards into the manufacturing context;

- Show how we are leveraging outside resources in the development of 
specifications and systems; and,

- Expand collaborations and gain industry endorsement for our technical approach to manufacturing, system application integration.

This paper describes the current state of the ongoing project. The future plans proposed for this project are described at the end of the paper.

\subsection{Schedule}

The initial focus for this project activity was the development of a short 15 minute demonstration and presentation that can be given to a wide audience. It is designed so that different SMMA Project Managers and staff members can deliver the presentation. It is also designed to be extensible so that any additions/changes can be woven in to the scenario over time.

The first internal demonstration of the systems and interfaces was completed in mid-July 1997. As such, the initial demonstration was biased towards making the best use of existing modeling capabilities at NIST. The demonstration may eventually be incorporated into the Manufacturing System Integration Division (MSID) Web site (6) as a publicly accessible information resource.

\section{Modeling Manufacturing Systems}

\subsection{Rationale for selecting VRML}

One of the main project objectives was to develop the hyperlinks, which tie proposed IMES, Application Protocols (AP), and standards into manufacturing context of the demonstration. It was not possible to implement hyper-linked data via hot links on objects in any of the $3 \mathrm{D}$ simulation tools that were available to the project. Based on the 
project objectives, Virtual Reality Modeling Language (VRML) (7) was determined to be the next best-suited development tool. Also, VRML has an inherent advantage that it is a platform independent language and is intended for the Internet.

\subsection{Manufacturing Context}

The manufacturing context of the project consists of a conventional machine shop and a high volume assembly line producing consumer products. This context is selected based on work leading up to and recommendations contained within the SIMA Background Study Document (8). Various machined parts and machining stations are used as test cases for the machine shop in the demonstration. The high volume assembly line is based upon the miter saw line from the Black and Decker facility in Fayetteville, North Carolina. A number of test parts are utilized from the Black and Decker (B\&D)* miter saw (Figure 1). SIMA project teams have focused on different miter saw components and subassemblies as test data for other project activities.

* No approval or endorsement of any commercial product by the National Institute of Standards and Technology is intended or implied. 


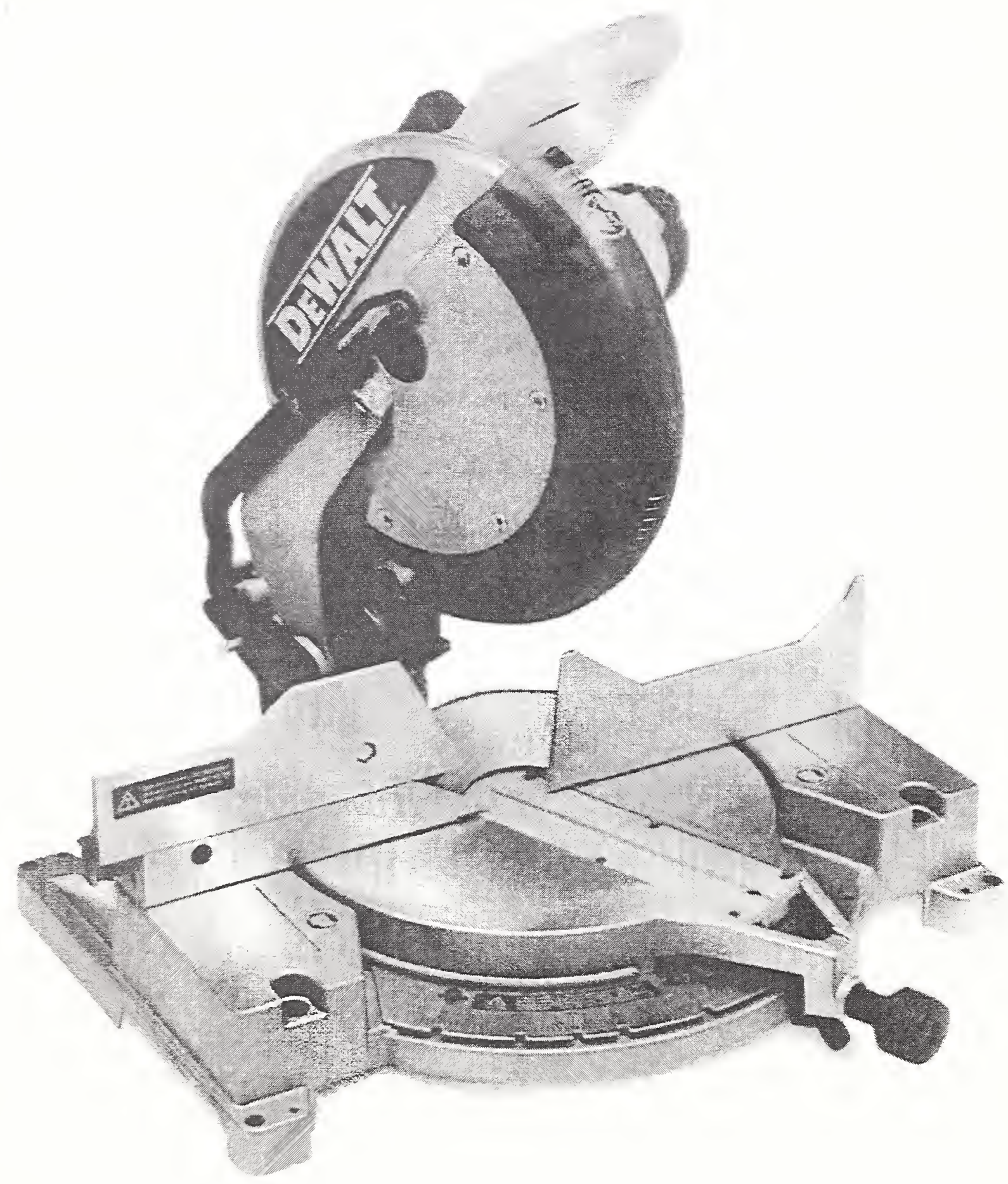

Figure 1: Black and Decker Miter Saw

2.3 Multi-leveled/Multi-faceted model

To illustrate the integration of the various activities in a virtual manufacturing system, the system was decomposed into levels and segments. The three major levels of 
the system are: Physical Systems, Information Systems, and System Architecture (Figure 2). Different types of manufacturing system objects, models, and data are displayed on each level. Closely related models and data within each level are shown on different segments. Models or representations of the same entity, which appear on different levels and segments, are aligned vertically (Figure 9).

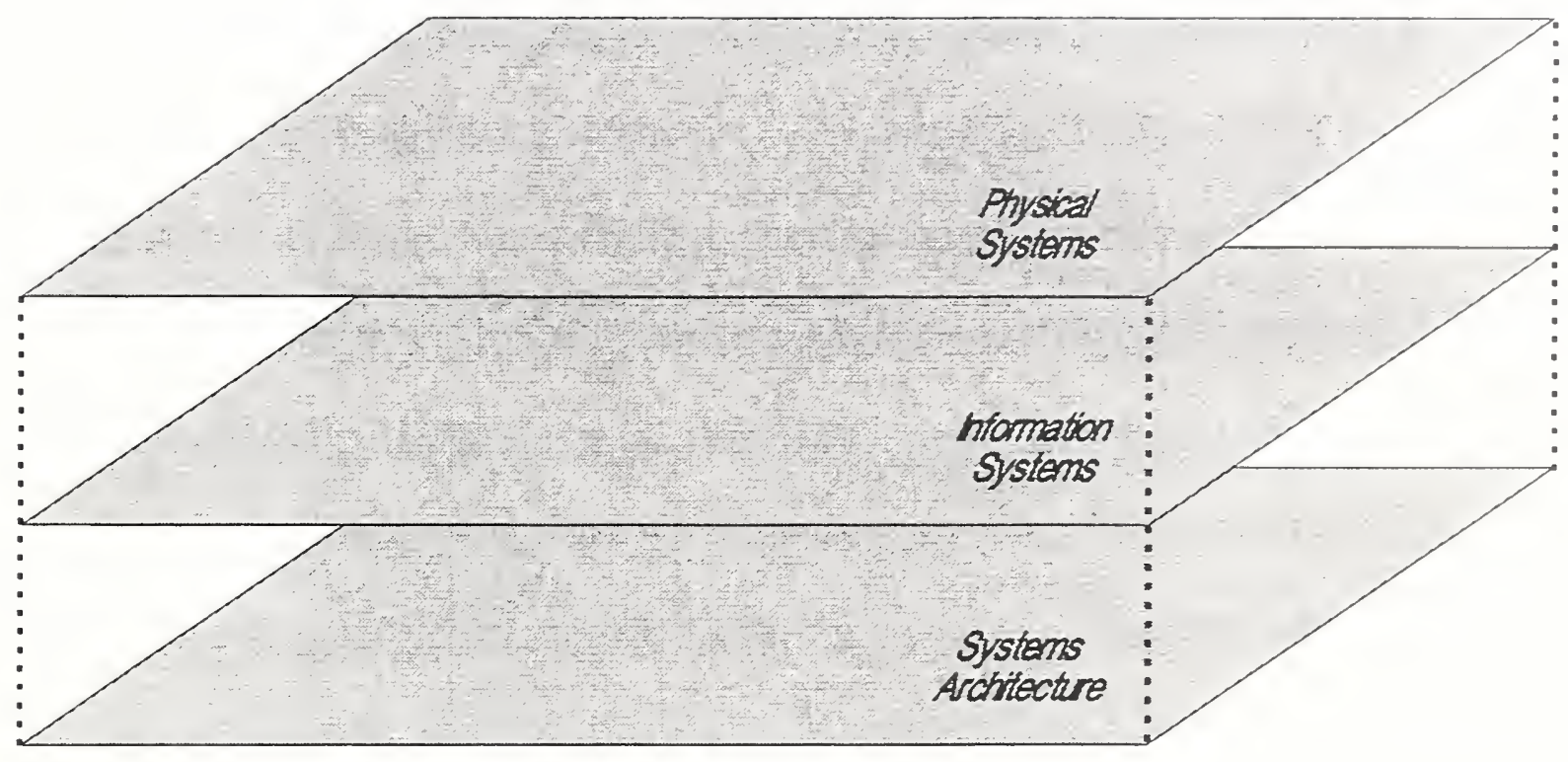

Figure 2 Levels in the Virtual Manufacturing System

The levels and segments modeled for the demonstration are described briefly below.

More levels and segments, which are envisioned for the future, are described at the end of this paper.

Physical Systems Level - This level shows the location and dynamic functioning of physical manufacturing systems and processes. At present, it consists of only one segment:

Physical Process Models - This segment shows three dimensional models of 
production machinery, material handling systems, engineering workstations, storage areas, finished products, work-in-process, raw materials, tooling, production and support staff, material removal and assembly operations. The model is based on an existing virtual production facility (9) which simulates the following physical systems:

- Cutting processes on a standalone numerically controlled (NC) machining workstation for production of power tool components or tooling (e.g., a mold) - Cincinnati T30 Milacron,

- A job shop consisting of a Hexapod machine tool, a coordinate measuring machine (CMM) and scheduling and shop floor data collection, and

- A conveyor-based assembly line for miter saw production.

Information Systems Level - This level shows the physical location and dynamic functioning of information systems and processes. It will consists of the following segments:

Information Systems Hardware - In this segment, an information flow simulation is implemented. It shows three-dimensional models of computers, monitors, printers, plotters, communications networks and various peripheral devices (bar code scanners, etc.). Electronic documents and messages travel on communications links, which are modeled as U-shaped channels, pipelines, or wires. The pipelines represent network connections between the computers in the engineering department, shop management offices, Product Data Management (PDM) (10) system, database management systems, shop machinery, and the shop floor. Data document icons move along the pipelines 
to illustrate data transfer among the different systems. The Monitors show the user interface of the applications.

Software Applications Segment- This segment will show the software applications resident on each computer system in the facility. Examples of software applications which are included are: design and analysis, process planning, NC programming, machine control, scheduling, shop floor data collection, tool management, inventory control, product data management, order entry, shipping and receiving.

System Architecture Level - This level shows static architecture, design, or interface elements associated with the Physical or Information Systems levels. It consists of the following segment:

Activity/Business Model - There is an Integration Definition for Functional Modeling ( $\mathrm{IDEF}_{0}$ ) activity model (11) segment for each level of decomposition in the SIMA Reference Architecture (12). Activity model nodes are located under the appropriate physical or information system where the activity is carried out.

\section{Demonstration Overview}

\subsection{Script summary}

The initial script for the demonstration was written based on the assumption that the objectives can be met using a single Silicon Graphics ${ }^{\mathrm{TM}}$ (SGI) workstation. But, during development of the models and subsequent integration, the number of polygons in the VRML models grew rapidly. So, in order to avoid loading delay, the scenario was 
divided into different sub-scenarios based on functionality. Each sub-scenario then was represented in a single VRML world.

\subsection{Worlds}

The demonstration is now comprised of seven VRML Worlds that are viewed in web browsers through separate UNIX processes. These processes utilize Netscape Navigator ${ }^{\mathrm{TM}}$ with the Cosmo Player ${ }^{\mathrm{TM}}$ plug-in installed. Also, to maintain continuity in the description, each world has a transition point. Each such transition point consists of visualization of VRML geometry as the last scene in that world. This geometry is depicted in the subsequent world as the first scene. The effect is such that as the worlds are switched, the audience visualizes the same geometry model giving the appearance of one continuous world. Using this transition point mechanism, switching from one VRML world to another is performed smoothly. Also, the multi-level model is shown only for World 4 and is planned for the other worlds in the future. The following is a description of the seven Virtual Worlds.

VRML World 1: The purpose of this world is to show the real world issues that SIMA is focusing on. This world consists of a series of background images that illustrate the manufacturing context at the Black and Decker facility that serves as a test case for SIMA. World 1 has 22 pre-defined viewpoints and includes images of the miter saw line at the facility. World 1 has the SIMA Reference Architecture document cover (12) as the transition point into World 2.

VRML World 2: The purpose of this world is to give an overview of the Design activity in the Product Realization Process (12). The product realization process 
comprises of all principal technical activities involved in the manufacture of products, including product design, manufacturing engineering process, production planning, and production activities. World 2 starts with the SIMA Reference Architecture Cover as the starting point. Here however, the reference architecture forms the cover of a notebook. Each mouse click on the notebook causes the pages to flip, revealing the $\mathrm{DEF}_{0}$ diagrams within the scope of the process represented in the world. The other primary visual in this world is a "magic carpet ride" on the Computer-Aided Design (CAD) document through a network and into a PDM server. Refer to Figure 3,4,5,6 and 7 for visual images from World 2 .

VRML World 3: This world starts with the SIMA Architecture as the cover of a notebook with the pages revealing the $\mathrm{DEF}_{0}$ diagrams pertaining to the activity of producing products within the product realization process. The activity of producing products involves the definition of the production schedules and the controlling of the flow of materials into and out of the production facility, and the execution of the production processes. This world gives an overview of casting and the scheduling activities involved in producing castings. The world includes a casting machine, a deburring machine and a trimming machine. It also has a table with a human operator seated at it. Located on the table is an image of an IMES chart, a computer with an image of the schedule on its screen, and one of the components of miter saw (the fence part). The interfaces specified in the IMES for this world are job orders, schedules, routings and job status. The machines were modeled using Deneb's IGRIP ${ }^{T M}$, the computer in 
VRML 2.0, and the fence part in Pro-Engineer ${ }^{\mathrm{TM}}$. Refer to Figure 8 for visual image from World 3.

VRML World 4: World 4 has the fence part as the starting point. In this world, the fence part is loaded into a fixture at a Cincinnati Milacron T30 Machining center. The machine center is a part of the multi-leveled model. The top level is the physical level with the T30 machine and a table. The table has a computer displaying a simulation image of the cutting process, a manufacturing data package (10) file folder, an image of an IMES chart and the SIMA Reference Architecture cover. For this world, the interfaces specified in the IMES chart are part designs, process plans, NC programs and cutting tool models. The user can flip through the pages of the manufacturing data package file folder by clicking on the file folder. The pages contain an image of the NC program, a process plan, and cutting tool models. The second level is the information level. Here, information flows relevant to the world are depicted using Graphic Interchange Format (GIF) images. The initial plan was to have information flows depicted through animated 3D models, but due to time constraints, images were used instead of $3 \mathrm{D}$ models. The third level is the system architecture level, which has an image of the "Realize Products" activity model (12) on it. The T30 machine tool was modeled using Deneb IGRIP ${ }^{\mathrm{TM}}$, and the table with computer and notebook were modeled using CosmoWorlds ${ }^{\mathrm{TM}}$ 1.0.2. Refer to Figure 9 and 10 for visual images from World 4. VRML World 5: The purpose of World 5 is to give an overview of the projects underway in National Advanced Manufacturing Testbed (NAMT) (13). The 
world consists of a Hexapod machining center, a CMM with a fence part on it, and a worktable. The table has a computer, an IMES chart and the SIMA Reference Architecture. The interfaces specified in the IMES chart in this world are PDM access protocol, Standard Data Access Interface (SDAI), manufacturing execution system objects, and inspection and Hexapod workcell objects. The computer displays various NAMT images in an animated sequence. Refer Figure 11 for visual image from World 5.

VRML World 6: The purpose of this world is to give an overview of the assembly activities in the miter saw assembly line. Along with the machines involved in the assembly, the world has an exploded view of a miter saw, which can be assembled via animation by clicking on it. The world also consists of a miter saw, a computer and an IMES chart all located on a table. The interfaces specified in the IMES chart in this world are product designs, assembly process specifications and plant layout. The miter saw was modeled in VRML 2.0 and the animation of the assembly of the miter saw components was developed using CosmoWorlds ${ }^{\mathrm{TM}}$. Refer to Figure 12,13 and 14 for visual images from World 6.

VRML World 7: The purpose of this world is to provide an overall summary of the whole demonstration. The world has a mitersaw, snapshots of activities shown in other VRML worlds, and an image of NIST. This world shows the connection between the standards developed at NIST and the activities that go in the making of a miter saw. Refer to Figure 15 for visual image from World 7. 


\subsection{Multi-Machine Implementation}

The Initial plan was to run the demonstration only on a single SGI workstation. Because the worlds developed had an enormous number of polygons, a single SGI machine could not run all worlds sequentially. Thus, three SGIs were used to run the worlds in a sequential manner. The first three worlds were loaded in the three SGIs. These SGIs were then connected to an overhead monitor display system. So as these worlds were displayed on the individual computers, the audience viewed it on the overhead monitors. After the first world was demonstrated, the demonstration moved onto the next machine to display the second world. At the same time, the overhead monitor connection was changed to the second SGI. This approach insured that the audience had a seamless visual presentation of the seven worlds. While the second world was being demonstrated, the first machine was loaded with the fourth world and so on.

\section{Development}

\subsection{Authoring tools used}

VRML was the primary language used for the work, even though other software packages such as Pro-Engineer ${ }^{\mathrm{TM}}$ and Deneb's IGRIP ${ }^{\mathrm{TM}}$ and Quest $^{\mathrm{TM}}$ were used for 3D modeling. CosmoWorlds ${ }^{\mathrm{TM}}$ was used as the authoring tool for VRML. The models from Deneb's IGRIP ${ }^{\mathrm{TM}}$ and Quest ${ }^{\mathrm{TM}}$ were translated into VRML using the NIST's Deneb-toVRML translator. Pro-Engineer ${ }^{\mathrm{TM}}$ has its own translator package along with the software. The human models were modeled using Transom Technologies JACK ${ }^{\mathrm{TM}}$ ergonomic software. 


\subsection{Interfaces and conversions}

Most of the models for the VRML worlds were developed using Deneb's IGRIP $^{\mathrm{TM}}$. Images were also used to describe some of the activities in the projects. Since images in Joint Photographic Experts Group(JPEG) format are compatible with VRML, images were converted to JPEG format using appropriate imaging software. Refer to Figure 16 for an overview of all of the applications, interfaces, and conversions that were used.

\subsection{Information sources}

Most of the translators convert the models into VRML 1.0. Subsequent translation to VRML 2.0 was done using a VRML 1.0 to VRML 2.0 translator (14). The translators employed were as follows:

1. Deneb to VRML 1.0: Developed at NIST (15).

2. Pro-Engineer ${ }^{\mathrm{TM}}$ to VRML 1.0: Packaged with the Pro-Engineer ${ }^{\mathrm{TM}}$ software.

3. $\mathrm{JACK}^{\mathrm{TM}}$ to VRML 1.0: Packaged with the $\mathrm{JACK}^{\mathrm{TM}}$ software.

\subsection{Lessons Learned}

During the project, various authoring tools were analyzed and were used to model some portions of the VRML worlds. Based on the experience with different authoring tools, we determined that it would be helpful to the developer to have the following few additional features in the authoring tools:

- The user interface in most of the authoring tools is still difficult to work with. This results in a long learning curve for the authoring tools. Most of the time 
is spent on figuring out what can be done with the particular tool.

- As the viewpoints are created, they are placed in sequence by the authoring tool. If the user wants to change the sequence, he can do it only through code. In other words, the authoring tool decides the viewpoint sequence rather than the user.

- The authoring environment's editor should be able to fully mimic what the plug-in does, i.e. it should be able to play the worlds in the editor.

- A performance analysis system is needed in the authoring tools. This feature could include ways to inform the developer the effect a new model will have on the performance.

\section{Future Plans:}

In the demonstration for the FY97, many of the goals outlined were met. In the future, the following developments are being planned:

The manufacturing facility would additionally contain the following physical work areas:

- Engineering department

- Shop management offices

- Tool room

- Material preparation area

- Inventory storage areas

The office areas will include terminals, desks, work tables, staff, bulletin boards, and data document objects. Physical prototypes of parts may also be introduced into these areas. 
Staff will have their functional titles written across their backs like football jerseys, e.g., design engineer, process planner, shop foreman, scheduler, tool room clerk/technician, machine operator, etc. In the multi-leveled model, the following additions are being considered:

Physical System Level: Additional segments, which are to be included in the Physical System Level are:

Plant Layout - This segment will show the two-dimensional plant layout drawing on the floor to the same scale as the physical models on level 1. This data will be obtained from a plant layout system. This segment will be further decomposed into additional plant layout segments, which breakout specific types of layout data.

Material Flow - This segment will show material flows for raw materials, components, products, and tooling. The data will be obtained from plant layout system. This segment will be further decomposed into additional material flow segments that breakout specific flow.

Information System Level: In the information system level, the following segment is to be included:

Object Models - This segment will show the data objects associated with each model on the physical systems or the other information system levels. Each object model will be represented as a notebook. Object attributes and values will be displayed on tabbed pages contained within each notebook.

Additional models which are to be included in the existing segments are 
Information System Hardware - In the information hardware segment, additional models to be included are:

The pipes from the information system level running up into computers or machinery at the physical level. File cabinets or drums under the shop (on the information level) will be used to show data repositories. These objects can be selected to show their contents and display individual documents or data items. Different icons will be associated with each document to identify its type. Translator boxes will be incorporated into pipelines or wires to show where data translations occur.

Software Application Segment - In this segment, translation software, which converts formats of electronic documents, will also be illustrated.

System Architecture Level: In the system architecture level, the following additional segments are planned:

Information Model - There will be two segments that contain the information models associated with the data and interfaces on the other levels. One segment will contain graphical Express-G information model (5). The other segment will contain the Express information models in text format. The Express toolkit (16) will be used to develop these models.

Control Logic - Control logic segment will be created as necessary to represent control hierarchies, control flowcharts, Petri nets and finite state machines. Software Design - This segment will be used to place pseudocode and other forms of software specifications which define the functionality of software 
modules implemented on the software applications segment.

\section{Conclusion:}

This paper presented the SIMA Technology Outreach project. The purpose of the project is to convey the integration and standardization activities underway within the SIMA projects to a wide audience. In this project, seven VRML worlds were developed to illustrate work in these projects. The project will continue to evolve over the years. Further development in the project includes the enhancement of the Physical, Information System and System Architecture levels contained in the VRML worlds.

Work described in this paper and the VRML demonstration was sponsored by NIST's System Integration for Manufacturing Applications (SIMA), and the U.S. Navy Manufacturing Technology Program and other programs. No approval or endorsement of any commercial product by the National Institute of Standards and Technology is intended or implied. The work described was funded by the U.S. Government and is not subjected to copyright.

\section{References}

1. Fowler ,J.E., "System Integration for Manufacturing Applications Program 1995 Annual Report", NISTIR 5839, NIST, Gaithersburg, MD, May 1996.

2. High Performance Computing and Communications: Towards a National Information Infrastructure, Report by the committee on Physical, Mathematical and Engineering Sciences, Federal Coordinating Council for Science, Engineering and Technology, Office of Science and Technology Policy, published by the National Coordination 
Office for HPCC, 1994

3. Technology for the National Information Infrastructure - A Supplement to the President's 1995 Budget, National Coordination Office for High Performance Computing and Communications, 8600 Rockville Pike, Bethesda, MD, 20894, USA

4. NIST home page - www.nist.gov

5. Kemmerer ,S.J., Fowler ,J.E., "Initial Manufacturing Exchange Specification”, NISTIR 5978, NIST, Gaithersburg, MD, 1997.

6. MSID home page - www.nist.gov/msid

7. Virtual Reality Modeling Language web page - vrml.sgi.com

8. Barkmeyer ,E., Hopp ,T.H., Pratt ,M.J., Rinaudot ,G.R., "SIMA Background Study", NISTIR 5662, NIST, Gaithersburg, MD, 1995.

9. Iuliano ,M.J., "Overview of the Manufacturing Engineering Toolkit Prototype", NISTIR 5730, NIST, Gaithersburg, MD, Oct 1995.

10. Iuliano ,M.J., "The Role of Product Data Management in the Manufacturing Engineering ToolKit", NISTIR 6042, NIST, Gaithersburg, MD, Aug 1997

11. Federal Information Processing Standards Publication 183[FIPS183] "Integration Definition for Functional Modeling (IDEFO)", NIST, Dec 1993, available from National Technical Information Service, U.S. Department of Commerce, Springfield, VA.

12. Barkmeyer ,E., et al "SIMA Reference Architecture: Activity Models", NISTIR 5939, NIST, Gaithersburg, MD, December 1996.

13. National Advanced Manufacturing Testbed - NIST Special Publication 913, NIST, Gaithersburg, MD, April 1997. 
14. VRML Repository - www.sdsc.edu/vrml

15. Deneb To VRML Translator - http://www.nist.gov/it/div894/ovrt/projects/mfg/ SIMA/deneb2vrml/deneb2vrml.html

16. An Introduction to the NIST PDES Toolkit - National PDES Testbed Report Series, NISTIR 4336, NIST, Gaithersburg, MD, May 1990. 


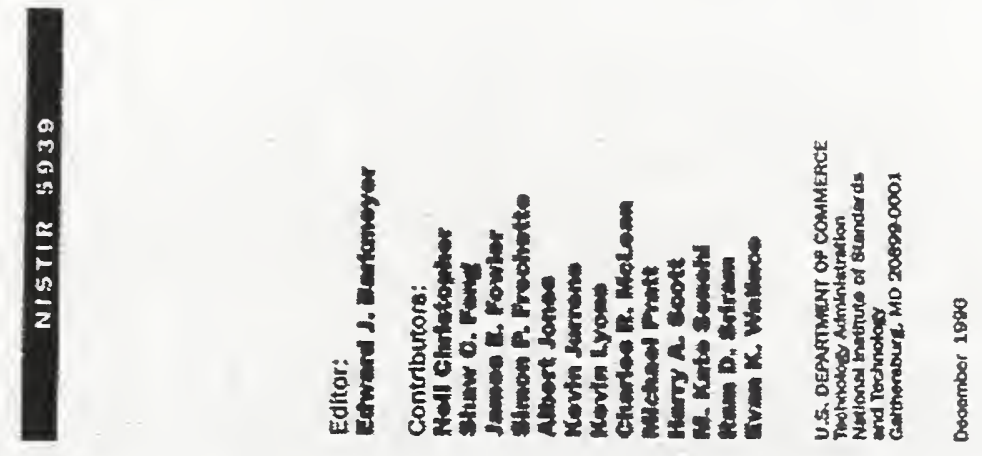

$\frac{5}{2}$

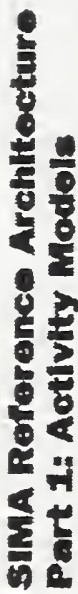




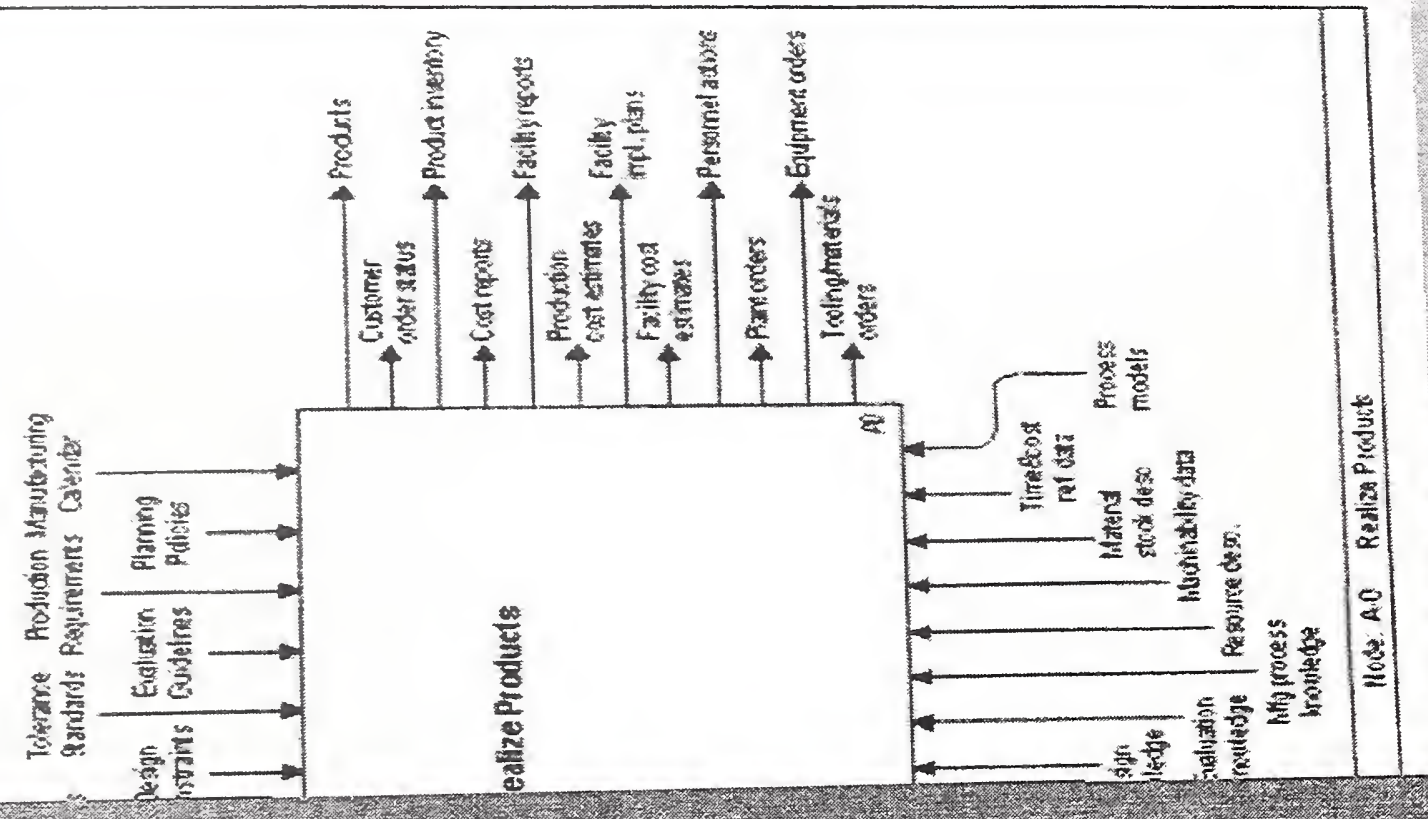

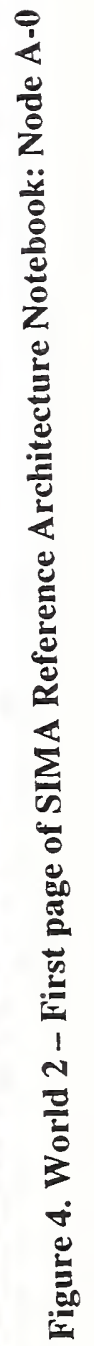




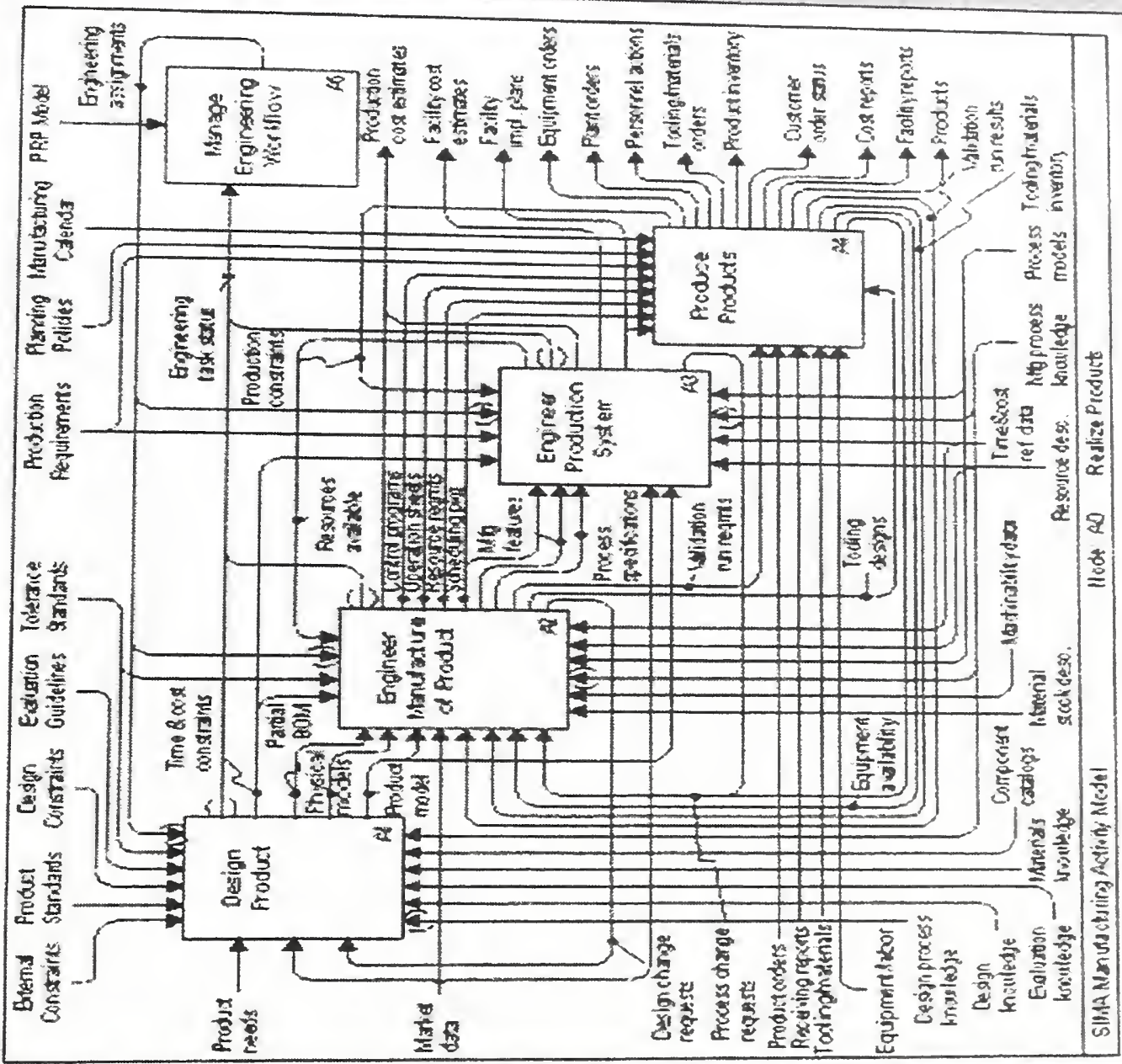

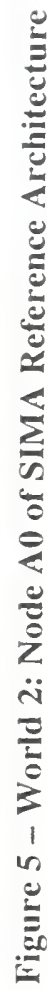




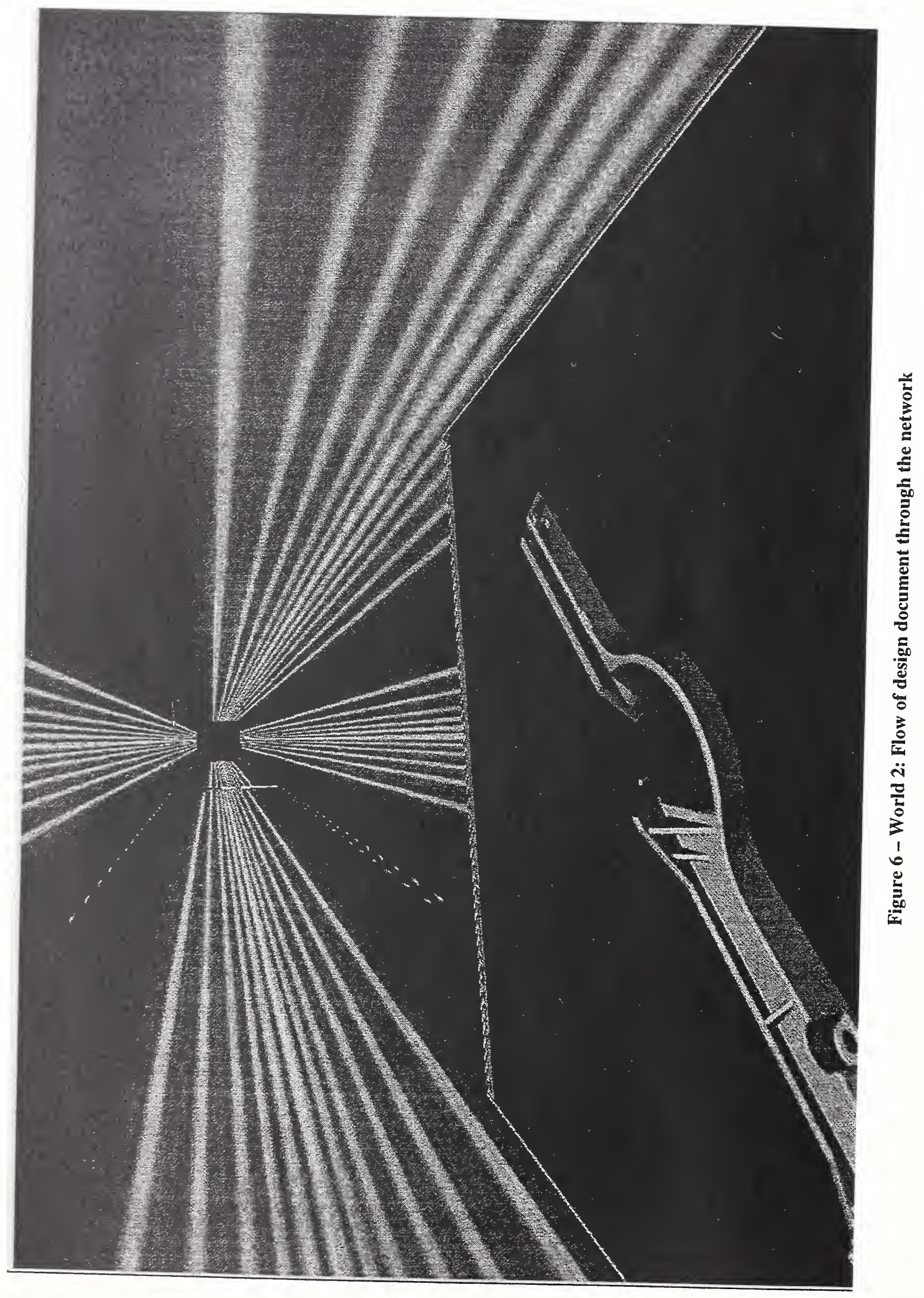




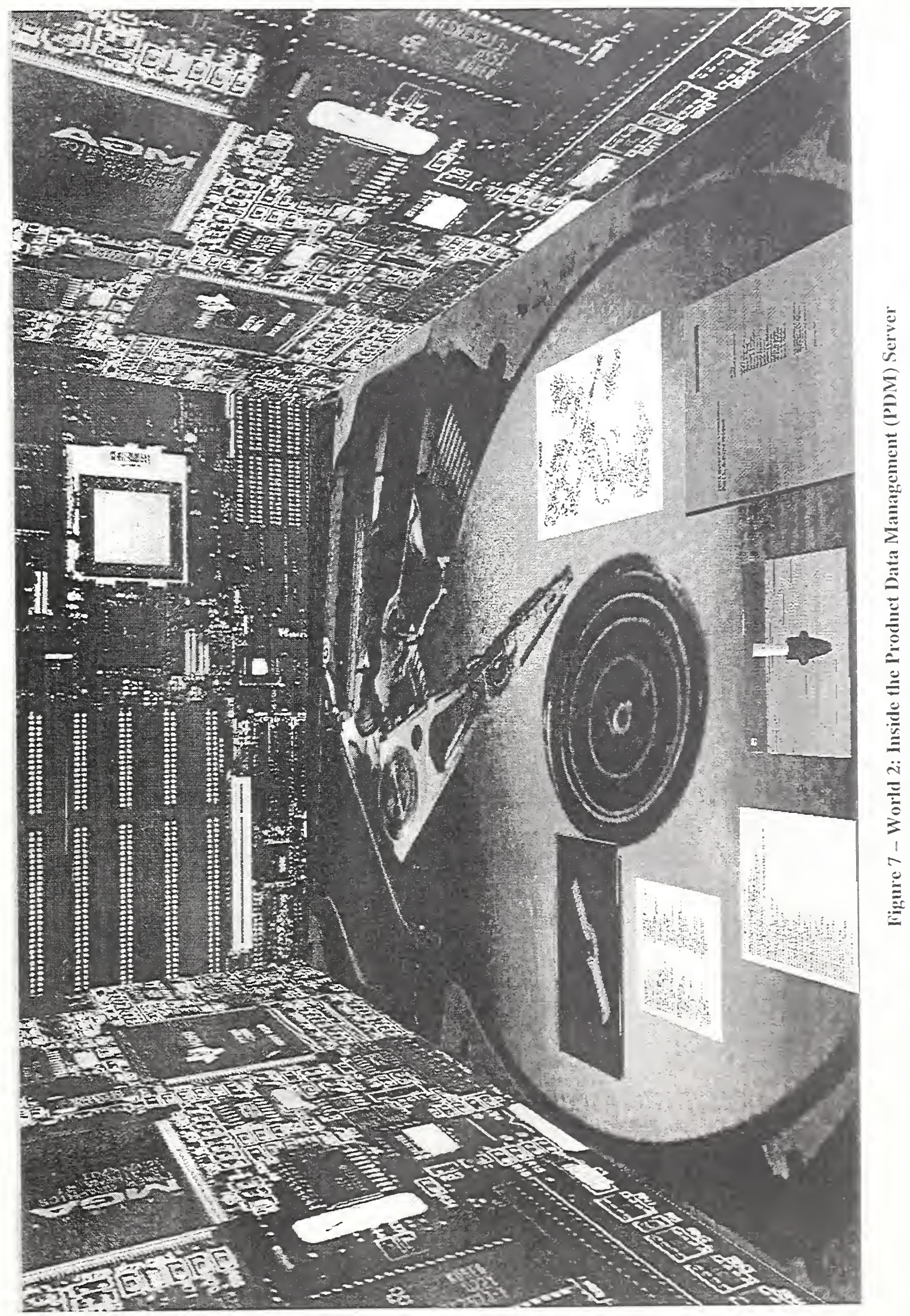




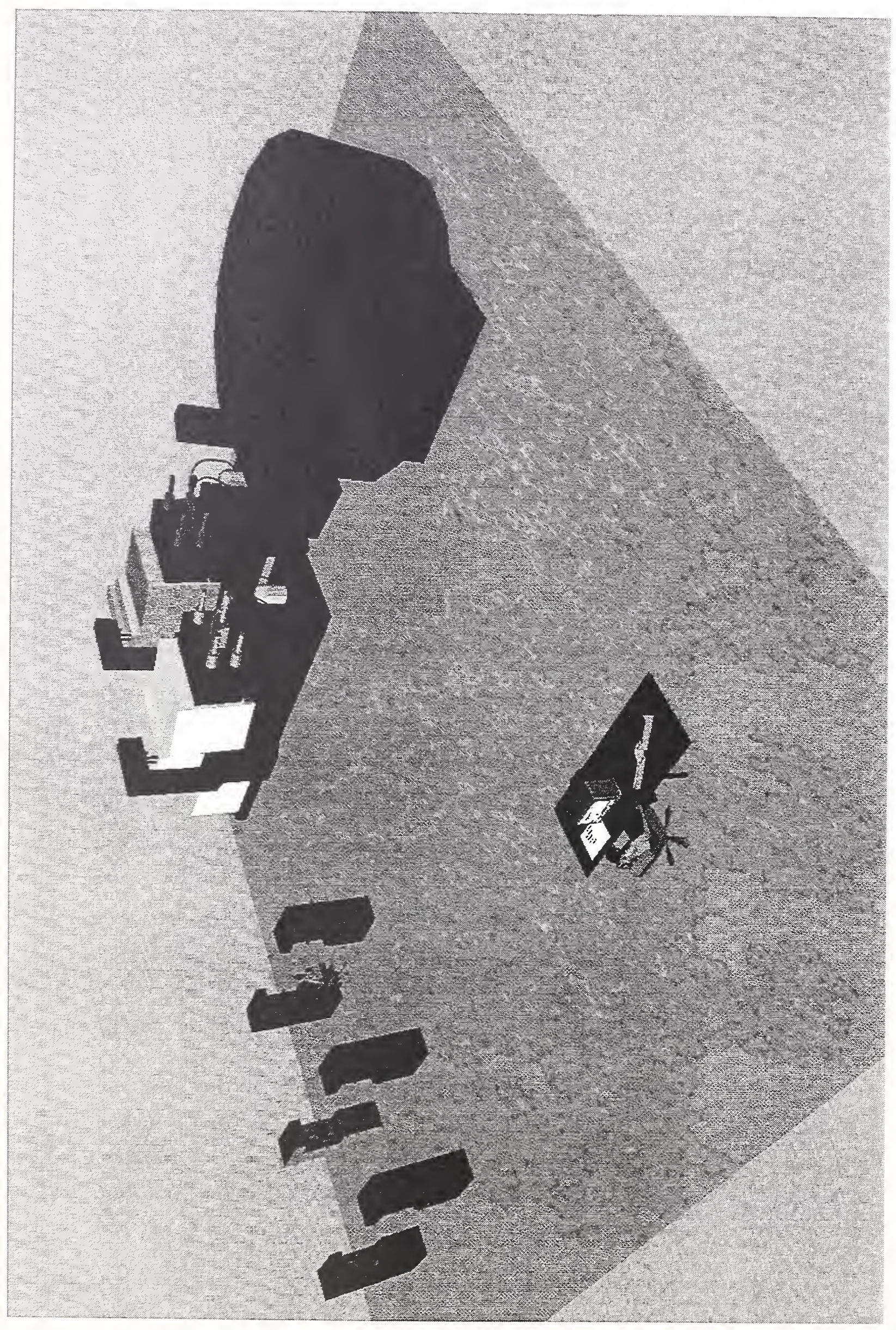

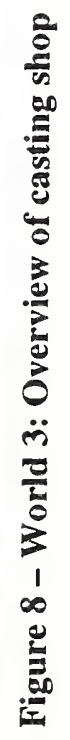




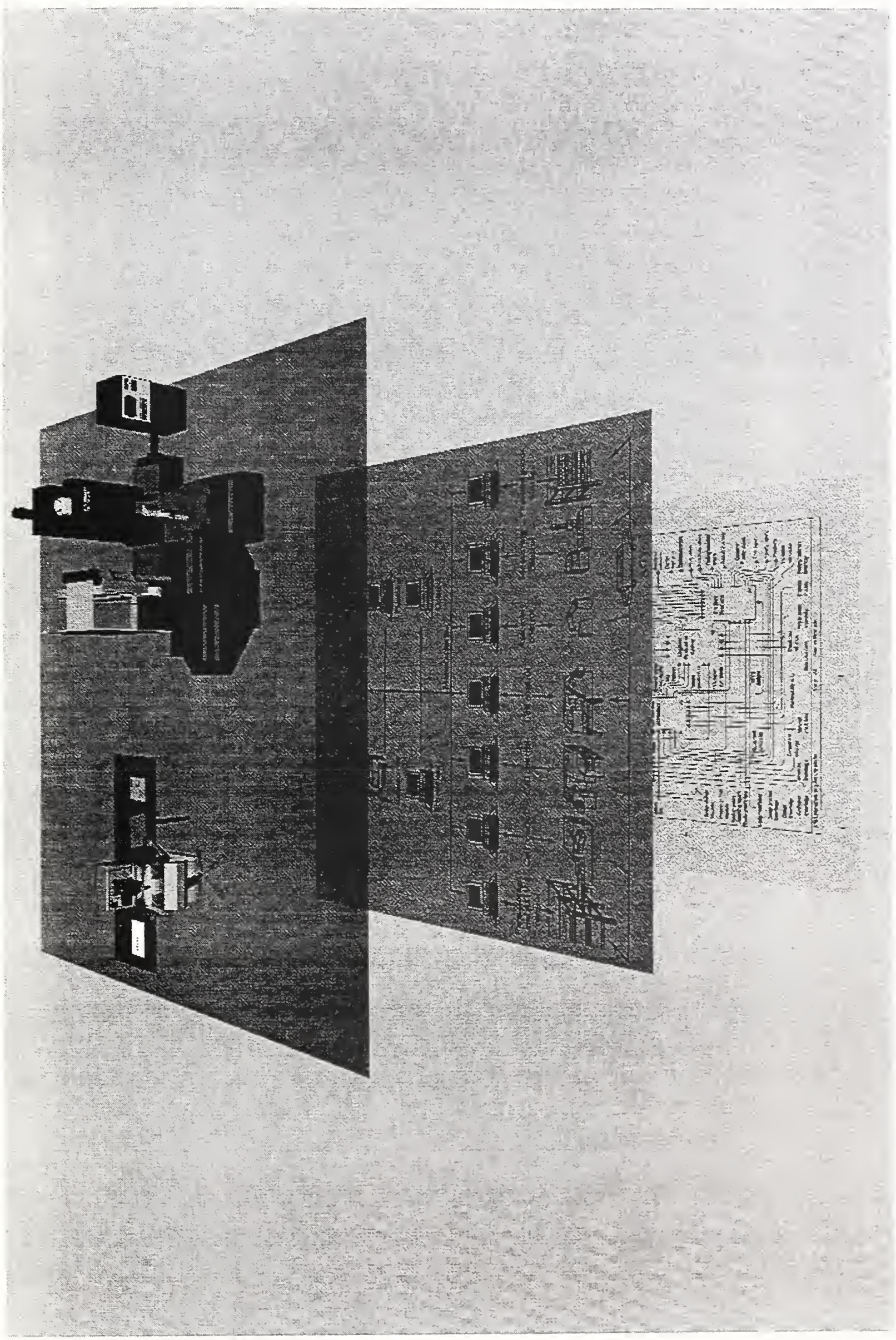

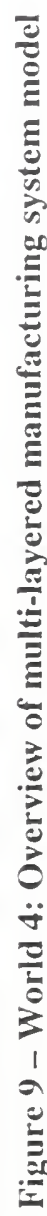




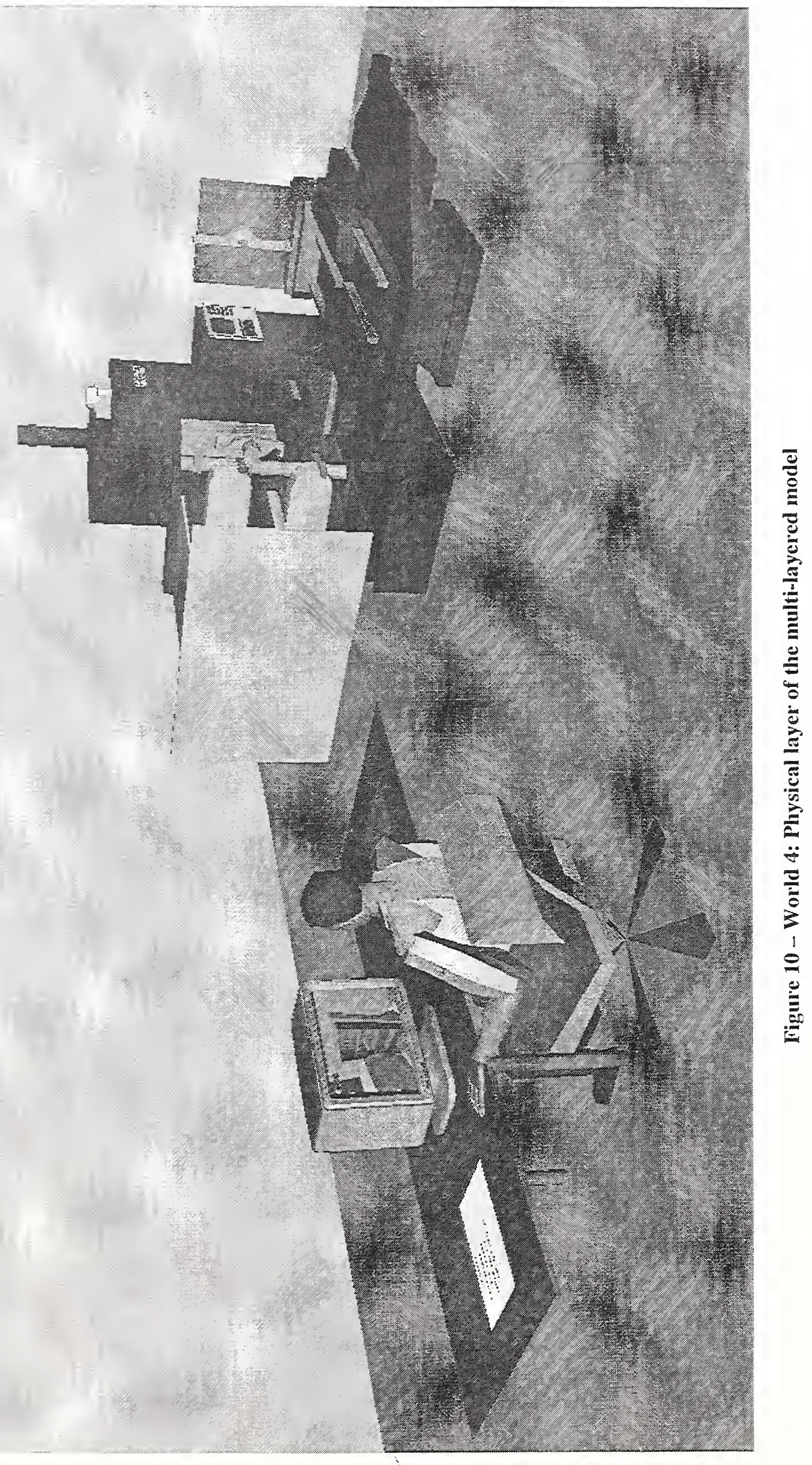




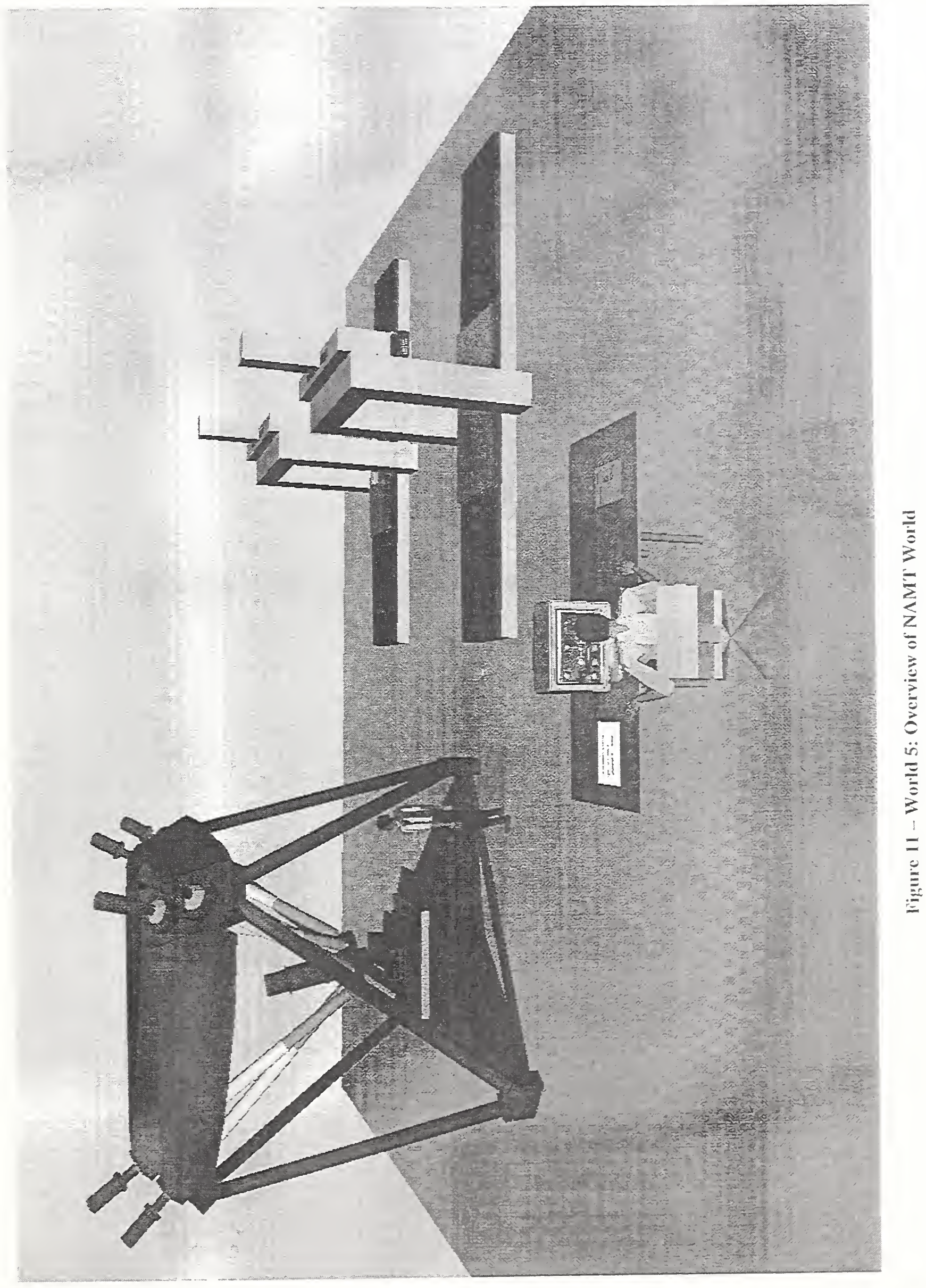





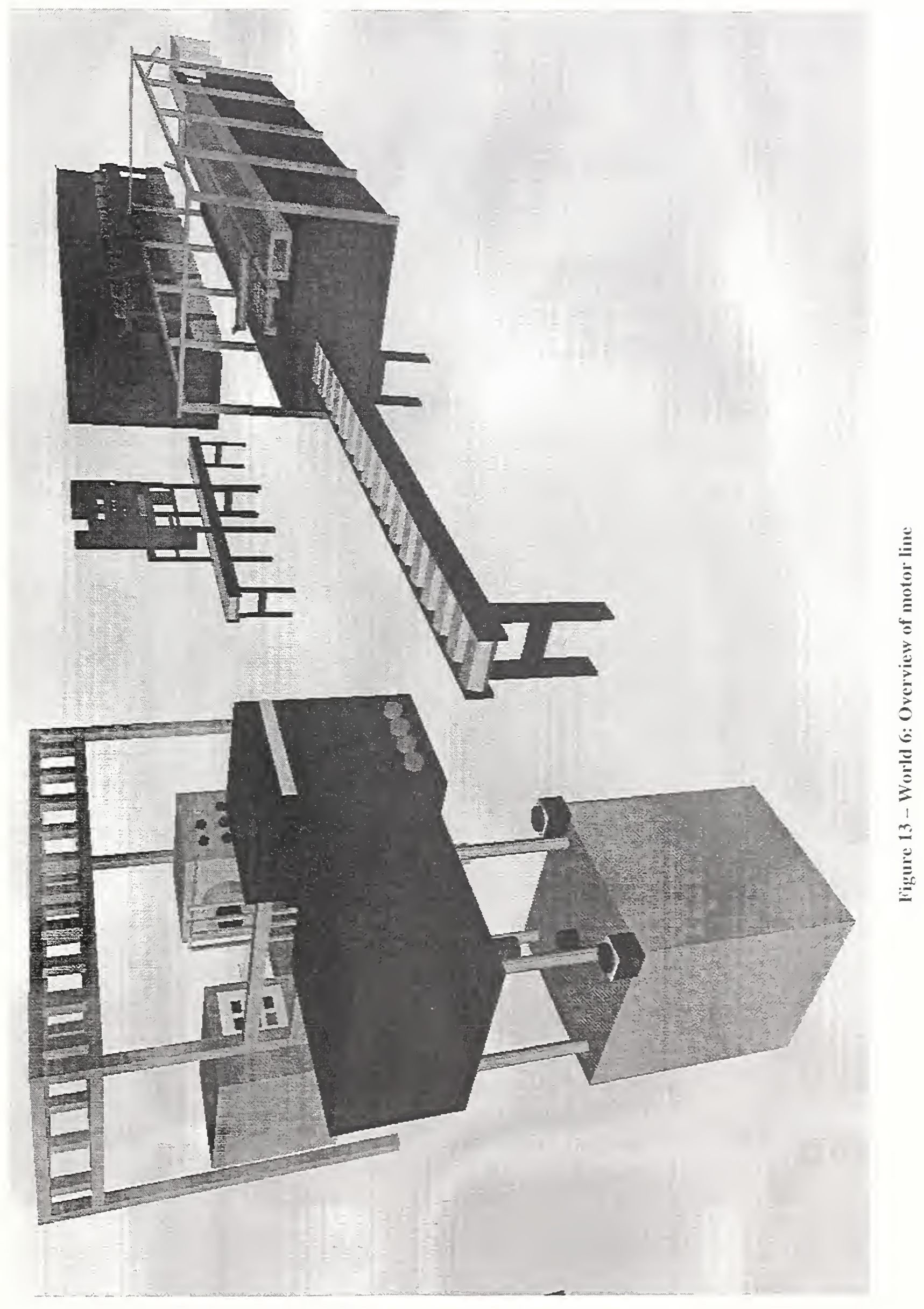




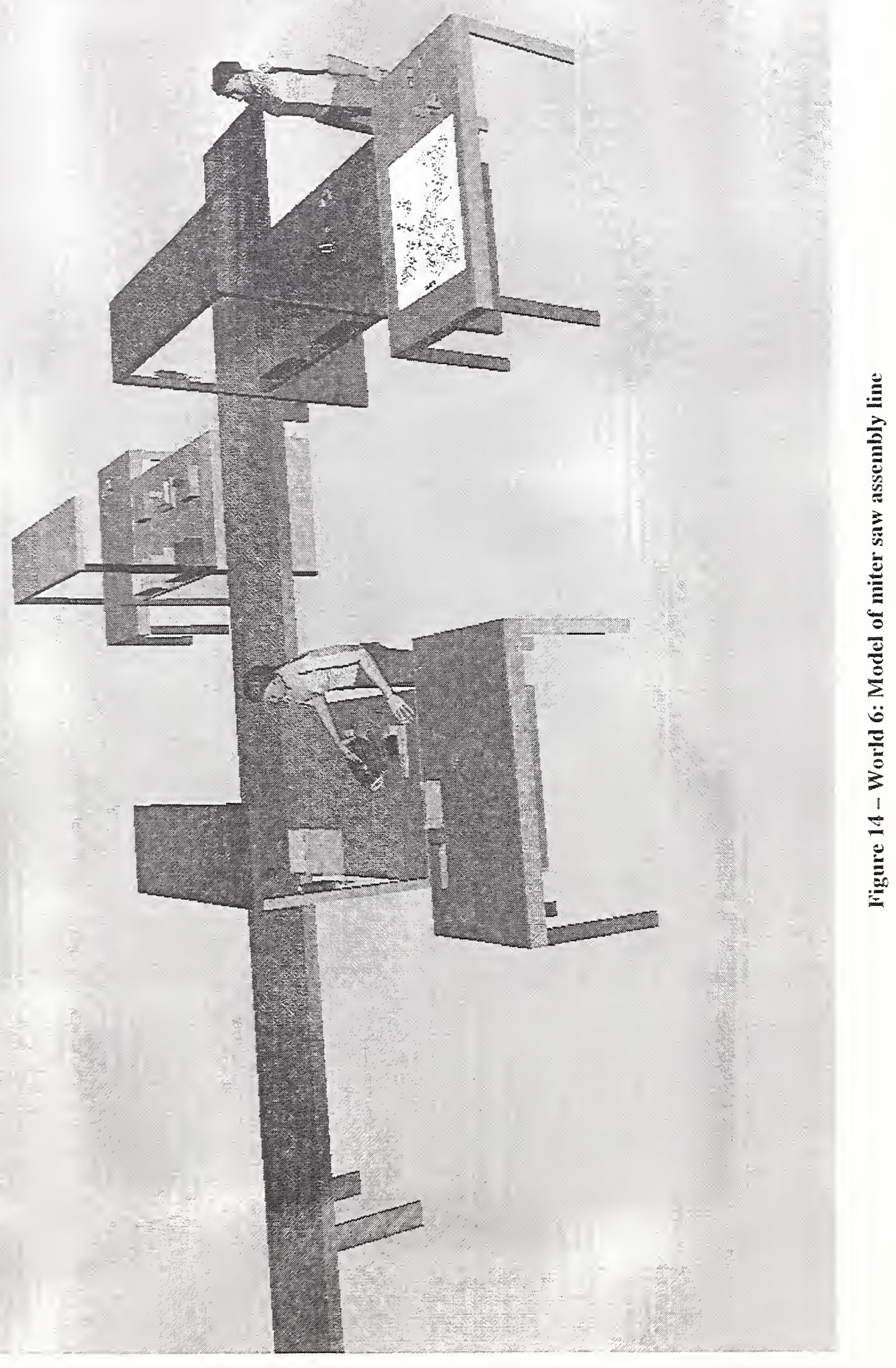




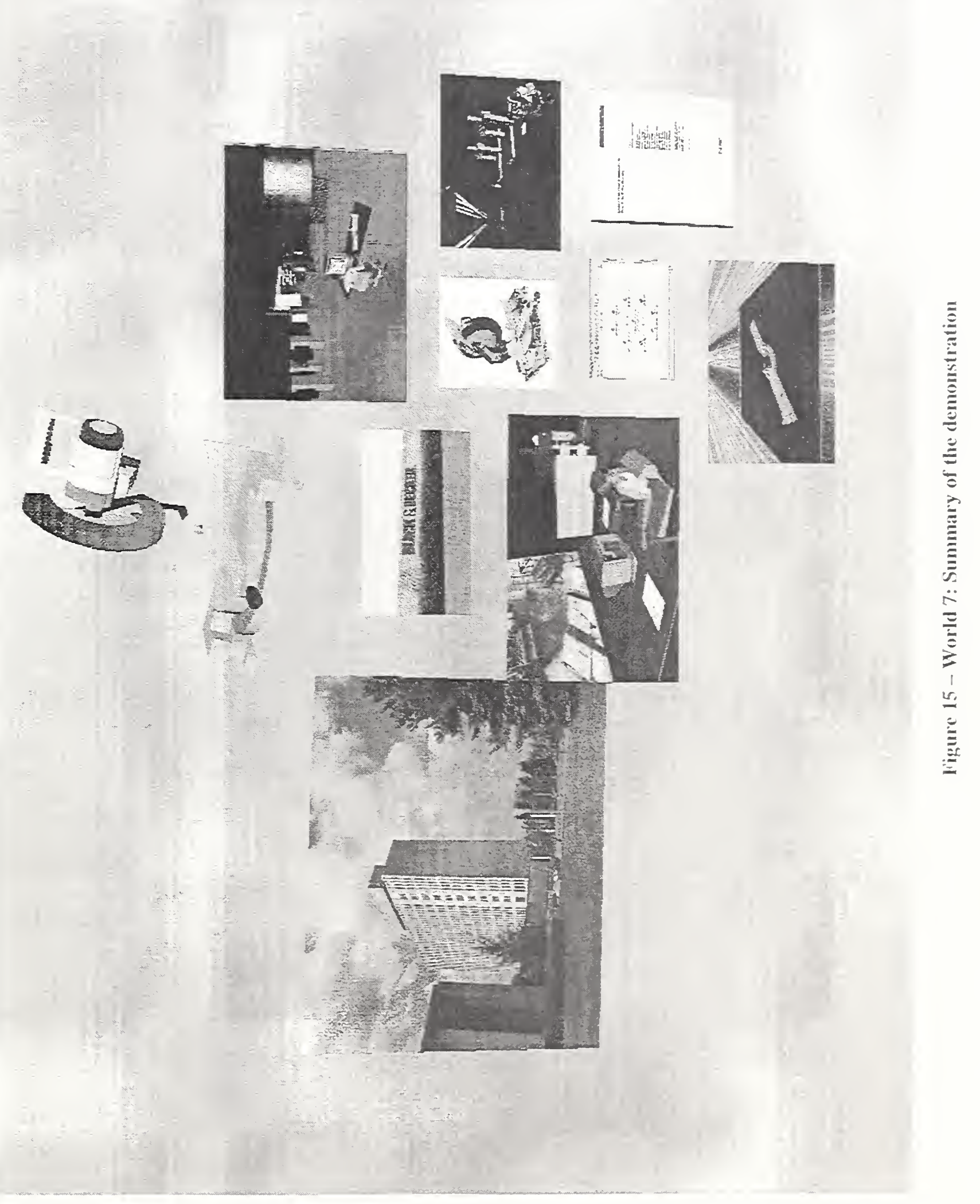




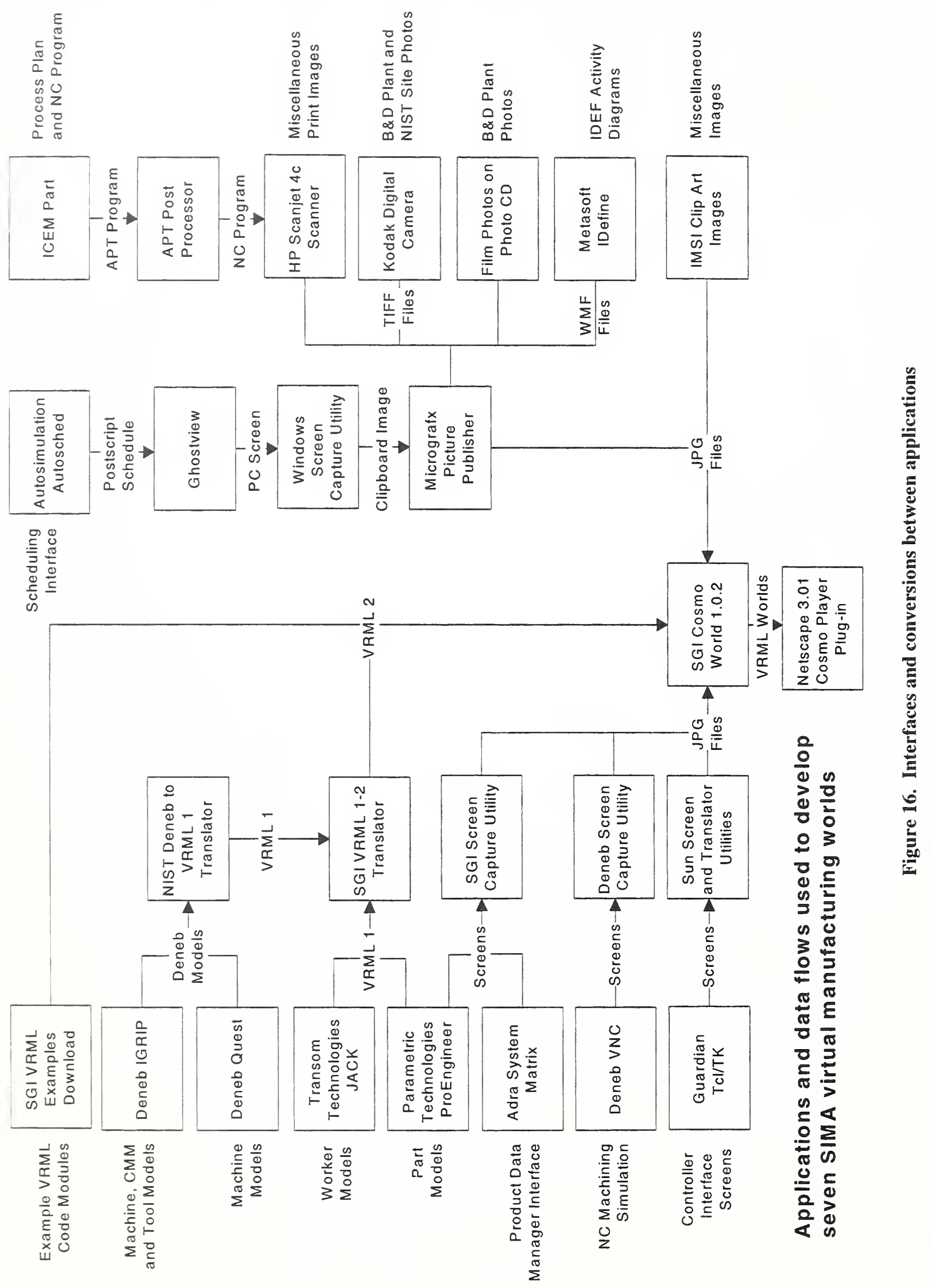




\section{Appendix A}

Following is the script used for narration during the demo. The narration was carried out simultaneously with the demonstration of the virtual worlds on the overhead monitor. Since synchronization between the narrator and the demonstrator was a major factor during the demo, the script was so arranged to maintain coordination between the two. 

SIMA Virtual Manufacturing Overview Demonstration Script

The demonstration is comprised of seven VRML Worlds that are viewed by separate Netscape processes with Cosmo Player plug-ins installed. The worlds are:

World 1 - Introduction

World 2 - Engineering

World 3 - Scheduling - Casting Shop

World 4 - Machining

World 5 - NAMT Inspection

World 6 - Assembly

World 7 - Conclusion

A key to reading this document follows. General background information is written in bold type. Scene descriptions and instructions to developers describe the implementation of the VRML World and are written italic. INSTRUCTIONS TO VRML OPERATORS AND ADVANCED MANUFACTURING SYSTEMS AND NETWORKING TESTBED (AMSANT) STAFF ARE WRITTEN IN SMALL CAPS. The text to be read by the Narrator is in regular text and follows each scene description. The VRML operator should not initiate the transition to the next scene until the narrator finishes the text in the current scene. The ( $\S \S \S$ Viewpoint Name) note indicates a shift to the next viewpoint in the VRML world. Viewpoints are given recognizable names that may not match the name in the VRML world code at this time.

\section{Loading Sequence}

- LOAD SGI O2 MACHINE 1 WITH WORLD 1 -

- LOAD SGI O2 MACHINE 2 WITH WORLD 2 -

- LoAd SGI O2 MACHINE 3 WITH WORLD 3 -

- LOAD SGI O2 MACHINE 1 WITH WORLD 4 -

- LoAd SGI O2 MACHINE 2 WITH World 5 -

- LOAd SGI O2 MACHINE 3 WITH WORLD 6 -

- LOAD SGI O2 MACHINE 1 WITH WORLD 7 - 


\section{WORLD 1}

SET OVERHEAD MONITOR TO DISPLAY SGI O2 MACHINE 1 (WORLD 1)

VRML World 1 contains a series of background images primarily illustrating the manufacturing context at Black and Decker that is serving as a test case for SIMA. The purpose of this world is to show that SIMA is focusing on real world problems. The manufacturing context for addressing SIMA problems is introduced.

Scene 1: Start with a view of earth from space with satellites relaying messages zoom into one virtual building which looks nominally like the Black and Decker building.

(§§§§ Earth View) The Systems Integration for Manufacturing Applications (SIMA) Program at NIST is developing data interface standards that will enable implementation of global manufacturing enterprises in the $21^{\text {st }}$ century. Industry needs a diverse set of standards to link together supply chains and integrate systems within individual manufacturing facilities. The SIMA Program is the primary program in the United States that is addressing these needs. Let's take a closer look at what it will take to integrate information systems within one large multinational corporation, Black and Decker. Black and Decker is just one of many organizations that is collaborating with the SIMA Program. (§§§§ Black and Decker Plant)

Scene 2: Zoom into North Carolina stopping in front of the Black and Decker Power Tools Plant.

The Black and Decker Corporation manufactures a broad range of products for the home and industry. Some examples of products manufactured by Black and Decker include hand-held power tools, kitchen appliances, and lawn and garden products. Facilities that produce these products are located around the world. SIMA Program staff have been working with the power tools plant in Fayetteville, NC, and others, to identify and evaluate industry's data integration requirements. (§§§§ Power Tools)

Scene3: Photo of assorted power tools

The Fayetteville Facility is the world's largest manufacturer of power tools. Millions of these products are manufactured and shipped from this plant each year. Some of the manufacturing processes found at Fayetteville include plastic injection molding, metal casting, machining, painting, and assembly. (§§§§ NIST Staff) 
Scene 4: NIST and BED Staff at the Fayetteville plant.

NIST and Fayetteville staff have selected one Black and Decker product as the

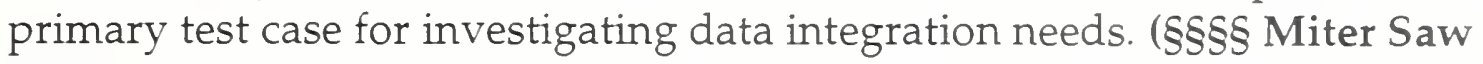
Photo)

Scene 5: Miter Saw Photograph

The product is the Model DW705 Miter Saw. The miter saw is used by construction contractors and home woodworkers to make precise angled saw cuts in wood. All of the processes mentioned before are found in the production

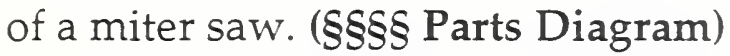

Scene 6: Assembly blowup drawing

The saw contains over 100 plastic and metal components. Miter saw components are either provided by subcontractors or fabricated at the Fayetteville Facility.

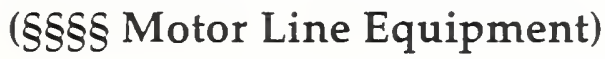

Scene 7: Various photographs of the motor line in quick succession

Saw motors are built and tested by highly automated systems. A wide variety of motor sizes and configurations are manufactured on these lines for different

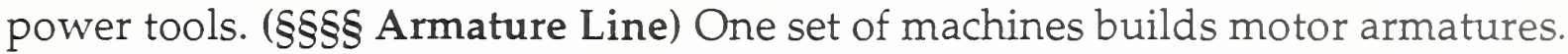
(§§§§ Winding Machine) Wire is automatically wound onto the armatures. (§§§§ Armature Tray) Finished armatures are loaded into trays for delivery to the final assembly area. (§§§§ Spindle Gear Press)

Scene 8: Various photographs of the miter saw line in quick succession ending with...

Final assembly operations are performed manually on individual product lines that typically measure less than 200 feet in length. On the miter saw line, the saw is built up step by step ....spindles are pressed into gears ( $\S \S \S$ Table Assembly) ... the table is assembled ( $\S \S \S \S$ Fence Assembly) ... the base and fence are added (§§§§ Conveyor Loading) ... subassemblies are placed on the conveyor for delivery to other stations ( $\S \S \S \S$ Armature) ... motor assemblies are built ( $\S \S \S \S$

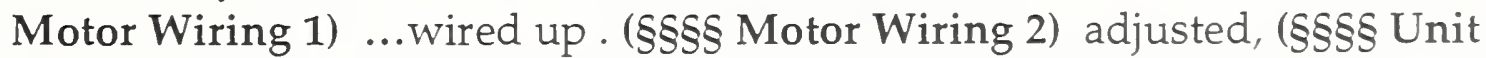

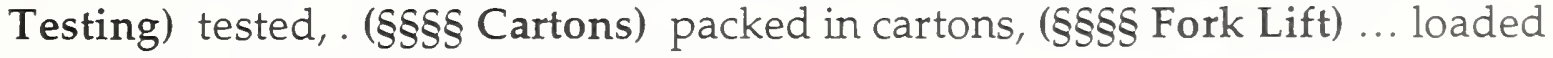
on pallets, and shipped. (§§§§ Trucks) 
Scene 9: ... Trucks at the loading dock

We have had a quick glimpse at some of the physical production operations that are required to produce products such as the miter saw. The integration and operation of information systems is much more difficult to see. Interfaces that allow information systems to work together are even more difficult to understand. (§§§§ SIMA Reference Architecture Cover)

Scene 10: Fly through the image of the truck to the SIMA Reference Architecture Document Cover. Zoom into the Architecture document and hold.

Simulation and virtual reality gives us new power to visualize a world of information that has always been hidden in the past. Using the power of VRML, we can now quickly take you back and forth between the virtual worlds of the information system domain and the real world of manufacturing. Along the way, we hope that you will better understand the integration issues that are being addressed by the SIMA Program.

AT THIS POINT, ANOTHER SGI MACHINE IS SELECTED FOR DISPLAY ON THE OVERHEAD MONITORS. THE COSMO BROWSER ON THE NEXT SGI MACHINE HAS BEEN PRELOADED WITH THE NEXT VRML WORLD.

WORLD 2

SET OVERHEAD MONITOR TO DISPLAY SGI O2 MACHINE 2 (WORLD 2)

VRML World 2 contains a series of 3-D VRML models, images, and diagrams that illustrate engineering data integration and product data management.

Scene 1: SIMA Reference Architecture Document Cover

In 1995, SIMA scientists and engineers worked together with industrial collaborators to define the SIMA Reference Architecture. The reference architecture addresses the integration of manufacturing software applications in the areas of design, planning, fabrication, and assembly of discrete electromechanical parts. Its scope is limited to design engineering, manufacturing engineering, production systems engineering and production activities. Other aspects of the manufacturing enterprise, such as product planning, distribution, and maintenance are not within the scope of the project or the architecture. (§§§§ Realize Products Node) 
Scene 2: Report opens and zooms to reveal the IDEF model A-0 node - "Realize Products"

IDEF is a modeling technique that is used by businesses to define their activities, systems, and the information supporting those activities. "Realize Products" represents all principal activities involved in the manufacture of products. ( $\S \S \S$ Realize Products Decomposition)

Scene 3: Flip page to reveal the A0 node that decomposes "Realize Product" into four activities

The product realization process is decomposed into "Design Product, Engineer the Manufacture of Product, Engineer Production System, and Produce Products." If applications are to work together, their interfaces must be formally documented and adhered to by system developers. Interfaces are needed between design, analysis, process engineering, and product data management systems. Let's take a closer look at the product design activity. (§§§§ AMSANT Engineering Stations)

Scene 4: Fly through the book to reveal one side of the image cube that shows a photograph of several engineers sitting at stations in the AMSANT lab. Turn the cube to see just one of the engineers sitting at a computer workstation with the PDM screen. Turn again to show a close up of the PDM star browser screen.

Design engineers store and retrieve their work using a product data management or PDM system. ( $\S \S \S$ Design station) PDM systems are designed to manage all product and process data within a manufacturing enterprise. (§§§§ Real PDM Screen) The SIMA Program is working with software vendors, through the Object Management Group, to develop standard interfaces to PDM systems. (§§§§Virtual PDM Screen)

Scene 5: Fly around or zoom through the browser image to the virtual computer world that shows a virtual computer station with the star browser. The view focuses on the screen. The browser image shrinks away and a shaded solid model of the Black and Decker "fence" part image appears.

The design engineer uses CAD modeling tools to specify product structure (bill of materials and relationships between component parts), part designs, part functions, shape, geometry, tolerances and materials. Other tools, such as finite element analysis (FEA), and process engineering use product data as an input. Virtual reality (VR) will give the design engineer new tools visualize parts and assemblies. Ultimately product data standards will need to be extended to support VR technology. SIMA is developing virtual reality modeling extensions 
to the Standard for the Exchange of Product Model Data, commonly called STEP. When the engineer is finished, the design is checked back into the PDM System. Let's follow the design document back to the product data manager...(§§§§ Network Fly Through)

Scene 6: Shrink the document, fly into the monitor and down the network cable to the product data manager on the file server. The document lands on a stack of designs in the PDM room. Other document types are visible in the room. A product data manager figure is sitting at a desk at the end of the room.

All engineering applications store and retrieve their documents using the PDM system. The PDM system provides configuration management, access control, and workflow management, among other functions. (§§§§ Inside PDM Server) Some examples of the other documents used by engineering include process plans, setup illustrations, machine programs, tooling data, manufacturing resource models, and plant layouts. SIMA is currently developing data interfaces for virtual design, process planning, manufacturing resource data, and plant layout. (§§§§ Architecture Document on Disk Drive)

Scene 7: Cruise to and zoom into the SIMA Reference Architecture document lying on the disk surface with the other documents.

Let's look at some of the other activities defined in the SIMA Reference Architecture.

AT THIS POINT, ANOTHER SGI MACHINE IS SELECTED FOR DISPLAY ON THE OVERHEAD MONITORS. THE COSMO BROWSER ON THE NEXT SGI MACHINE HAS BEEN PRELOADED WITH THE NEXT VRML WORLD.

WORLD 3

SET OVERHEAD MONITOR TO DISPLAY SGI O2 MACHINE 3 (WORLD 3)

VRML World 3 contains a series of 3-D VRML models, images, and diagrams that illustrate scheduling and the casting portion of the production facility.

Scene 1: SIMA Reference Architecture Document cover is displayed. Open the Architecture document and position the viewer to reveal the "AO Realize Products" page with "A4 Produce Products" node highlighted. Pause for a moment. Turn another page to "A4 Produce Products" with the "A44 Schedule Jobs" node highlighted. 
The SIMA Program is working with scheduling, simulation, and shop floor data collection system vendors to specify data formats for job orders, routings,

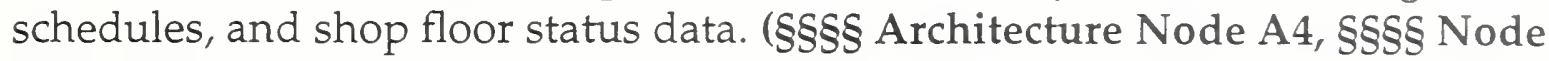
Close Up)

Scene 2: Zoom into the" A44 Schedule Jobs" node and fly through the page into the casting facility. Fly around the casting facility showing the different machines and workstations.

Many of the miter saw components are fabricated by casting processes. ( $\S \S \S \S$ Casting Area Overview) The SIMA Program has used the casting facility as a focus for scheduling and shop floor data collection data interfaces. (\$§§§

Deburring Machine) Some of the machines found in this area include deburring. . (§§§§ Casting) ... hot metal casting, . (§§§§ Trim Machine), ... and trim machines remove the flashing from cast parts. Shop floor data collection systems are used to track the status of production jobs. ( $\S \S \S \S$ Scheduling Table)

Scene 3: Overview of Scheduling Table

The SIMA Program uses several commercial scheduling and shop floor data collection systems to evaluate production management interfaces. Simulation software has been used to create a virtual production facility for job scheduling (§§§§ Scheduling Interfaces)

Scene 4: Briefly show the list of interfaces page on the table and scheduling system image on the screen.

Principal outputs of SIMA are Initial Manufacturing Exchange Specifications or IMES documents. These documents are typically data interface specifications between manufacturing applications. An example of an IMES is the interface for production management data. This IMES covers job orders, schedules, and shop status data. (§§§§ Scheduling Monitor) Jobs are scheduled and run through the virtual facility which emulates the behavior of real production facilities. Status data is collected and jobs are rescheduled. (§§§§ Fence Part on Table)

Scene 5: Proceed to the end of the table where the "fence" part is resting. (The color of the table is the same as the pallet on the Cincinnati Milacron T30 machining center.) Zoom into the part and hold.

The fence part is a typical cast part. After cast parts are trimmed and deburred, they are typically machined. 
AT THIS POINT, ANOTHER SGI MACHINE IS SELECTED FOR DISPLAY ON THE OVERHEAD MONITORS. THE COSMO BROWSER ON THE NEXT SGI MACHINE HAS BEEN PRELOADED WITH THE NEXT VRML WORLD.

WORLD 4

SET OVERHEAD MONITOR TO DISPLAY MACHINE 1 (WORLD 4)

VRML World 4 contains a series of 3-D VRML models, images, and diagrams that illustrate the MACHINING portion of the production facility.

Scene 1: Fence part is in the center of screen. Zoom back away from the part to show the part mounted on the Cincinnati Milacron T30 machining center. Zoom back further to show three levels under the machining center.

(§§§§ Fence Part on Machine, §§§§ Multi-Layer View) Let's look at how the physical production systems, an information systems diagrams, and the SIMA Reference Architecture tie together to give us a complete the picture of our virtual production facility. Standardized models of machines and cutting tools will help eliminate multiple, incompatible representations of data. Data can be created once and then used by multiple software applications, e.g., design, process planning, NC programming, and simulation systems. (§§§§ Machining System Diagram)

Scene 2: Zoom into the second level and cruise the system diagram level and hold to show a system diagram showing computer applications for design, process planning, NC programming, post-processing, and machining.

The SIMA Program uses commercial computer-aided design, process planning, and NC programming systems to generate machining data. The product data management system manages workflow and provides configuration control of

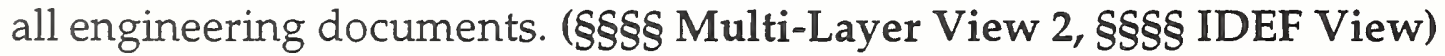

Scene 3: Zoom back to show the three levels again. Zoom into the IDEF level and briefly cruise the IDEF model. Back off to show the three levels again and cruise to the table next to the machine tool.

The functions and data flows between the commercial software packages adhere to the IDEF specifications found in the SIMA Reference Architecture. (§§§§ Multi-Layer View 3, §§§§ IMES View)

Scene 4: The monitor on the table is showing a close up simulation image of a part being machined from Deneb's Virtual Numerical Control (VNC). On the left of the monitor is 
an image of a sheet of paper that shows the IMESs and standards being worked which are relevant to machined parts manufacturing. On the right of the monitor is a file folder with manufacturing data package on the cover. A copy of the architecture document sits to the right of the folder.

The SIMA Program is developing IMES or working with standards organizations to develop a number of interfaces for machined parts production. Interfaces support the flow of information between process planning and machining, process plan data formats, and manufacturing resources data. (§§§§ VNC Simulation) The AMSANT facility is capable of simulating the production of machined parts in the computer. A joint activity with the U.S. Navy is focusing on the interfaces for integrating engineering tools and manufacturing data validation. (§§§§ Mfg. Data Package Folder)

Scene 5: Zoom to the file folder and hold. The file folder opens and pages through a part model, a process plan, an NC program, and cutting tool models. A hold occurs on each document.

Let's take a look at some of the different types of data found in a manufacturing

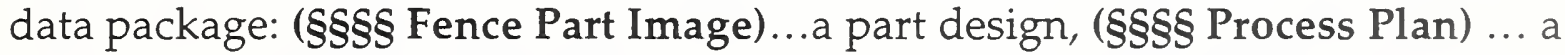

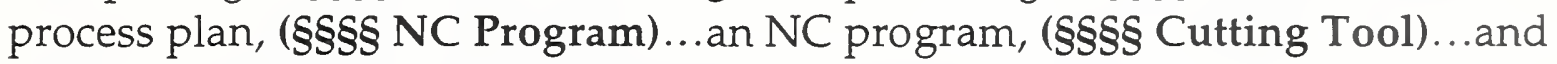
cutting tool models. (§§§§ Architecture Document Cover)

Scene 6: Cruise to the SIMA Reference Architecture Document resting on the end of the table and hold.

AT THIS POINT, ANOTHER SGI MACHINE IS SELECTED FOR DISPLAY ON THE OVERHEAD MONITORS. THE COSMO BROWSER ON THE NEXT SGI MACHINE HAS BEEN PRELOADED WITH THE NEXT VRML WORLD.

\section{WORLD 5}

SET OVERHEAD MONITOR TO DISPLAY MACHINE 2 (WORLD 5)

VRML World 5 contains a series of 3-D VRML models, images, and diagrams that illustrate NAMT INSPECTION portion of the production facility.

Scene 1: SIMA Reference Architecture Document cover is displayed. Open the Architecture document and position the viewer to reveal the "A45 Control and Execute Production" page with "A454 Control Equipment" node highlighted.

(§§§§ Architecture Document Cover) Let's take a look at a framework that is being developed to control systems down on the shop floor. (§§§§ IDEF Control 
Equipment) This activity focuses on the "Control Machinery" activity in the SIMA Reference Architecture. (§§§§ NAMT Overview) This work is being carried out as a joint effort between SIMA and the National Advanced Manufacturing Testbed. (§§§§ Hexapod)

Scene 2: Fly through the page to reveal a production area consisting of the hexapod machine, a coordinate measuring machine, and a table. Slowly cruise the production area stopping at the table.

The NAMT Framework activity has focused on the control of a workstation and machines. Machines include a hexapod machining center tool and a coordinate measuring machine. The hexapod is a non-traditional machine tool based upon a Stewart platform architecture. (§§§§ Inspection Machine) Coordinate measuring machines are used to perform mechanical measurements on parts. (§§§§ NAMT Interfaces)

Scene 3: Briefly look at the IMES document and standards page to the left of the monitor. Zoom into the monitor and hold. The monitor is displaying the NAMT control screen demonstration.

Interfaces under development include product data management system access protocol, standard data access interface, manufacturing execution system objects, inspection and hexapod work cell controller objects. (§§§§ NAMT Monitor Screen 1)

Scene 4: Step through the NAMT control screen demonstration by shrinking each image and displaying the next image on the screen.

On the computer, we can see a display which shows the command and status message transactions which control the sequence of operations within the workstation. The screens show jobs being entered, retrieval of status and control data, tasking of the inspection work cell, and its control. (§§§§ Monitor Screen 2,

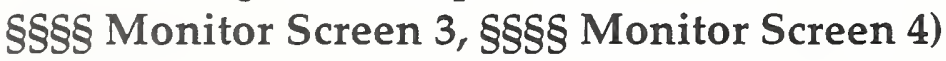

Scene 5: Cruise by the folder and zoom into the SIMA Architecture Document sitting at the end of the table.

The final phase of production is to assemble the product. (§§§§ Architecture Document Cover) 
AT THIS POINT, ANOTHER SGI MACHINE IS SELECTED FOR DISPLAY ON THE OVERHEAD MONITORS. THE COSMO BROWSER ON THE NEXT SGI MACHINE HAS BEEN PRELOADED WITH THE NEXT VRML WORLD.

\section{WORLD 6}

SET OVERHEAD MONITOR TO DISPLAY MACHINE 3 (WORLD 6)

VRML World 6 contains a series of 3-D VRML models, images, and diagrams that illustrate final assembly portion of the production facility.

Scene 1: SIMA Reference Architecture Document cover is displayed. Open the Architecture document and position the viewer to reveal the "A14 Produce Detailed Designs" page with "A146 Finalize System/Component Design" node highlighted.

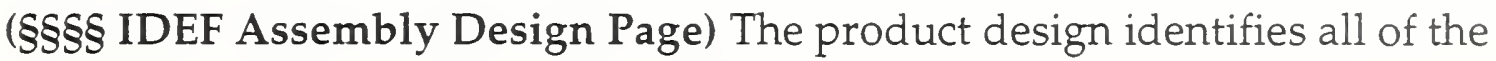
component parts and their relationship to each other. The STEP standards is defining information models and interfaces for defining assembly data.

Scene 2: Zoom through the page and hold on a blown up model of a handheld radial saw. Bring the components together to show an assembled product.

( $\S \S \S$ Miter Saw Assembly Implosion) Engineers use the design data to identify constraints and plan the assembly process that brings all of the components together.

Scene 3: Cruise the assembly facility showing the automated motor line, cruise the along the miter saw assembly stations (shelves of completed miter saws are in the background),.

(§§§§ VR Motor Line 1) Let us take a look at some of the processes going on in the assembly area. One portion of the assembly area is the motor line where armatures and field coils are assembled. (\$§§§ VR Motor Line 2-4) This line is highly automated and synchronized. (§§§§ VR Assembly Area 1-3) Final assembly of the miter saw is primarily a manual operation that is performed by assembly line workers. Process Engineers must also layout the workstations on the production line and balance operations so that the line flows smoothly. SIMA is working with simulation vendors to develop interfaces for modeling humans in the manufacturing workplace.

Scene 4: Stop at a table with the IMES page and a completed miter saw. Hold on the miter saw 
(§§§§ Assembly Interfaces ) SIMA is working on data formats for assembly process specification and production line layout. We have now seen just a sampling of the types of data required to produce a complex product such as the miter saw. ( $\S \S \S$ Completed Miter Saw Assembly) But we have only shown you the tip of the iceberg, there are many other types of data which also must be standardized.

AT THIS POINT, ANOTHER SGI MACHINE IS SELECTED FOR DISPLAY ON THE OVERHEAD MONITORS. THE COSMO BROWSER ON THE NEXT SGI MACHINE HAS BEEN PRELOADED WITH THE NEXT VRML WORLD.

WORLD 7

SET OVERHEAD MONITOR TO DISPLAY SGI O2 MACHINE 1 (WORLD 7)

VRML World 7 contains a series of 3-D VRML models, images, and diagrams that provide a summary and conclusion to the demonstration.

Scene 1: The completed miter saw is displayed. Zoom back to show a cluster of images from different points in the demonstration and hold. The images include: the front of the Black and Decker Plant, the completed miter saw, the SIMA Reference Architecture Document, engineering in the AMSANT facility, a document flying through the network, the scheduling/casting shop, the machine tool, the NAMT hexapod/CMM area, and the assembly area.

Information standards must be developed for each data type in order to integrate the many different activities that make up design, planning, and production. (§§§§ Demo Image Cluster) A long-term objective of the SIMA Program is to develop standards that will allow manufacturers to readily integrate off-the-shelf software that performs these functions. We believe that these standards will ultimately play a major role in improving the productivity of industry. ( $\S \S \S \S$ NIST and Cluster View)

Scene 2: Zoom farther back to reveal an image of the front of NIST (and the previous images) and hold.

The SIMA Program at NIST is the principal activity within the United States that is dedicated to manufacturing systems integration. The program is specifying interfaces, developing test cases, providing industry with standard reference data, and handbooks in support of product and process engineering. SIMA is working with manufacturers, software vendors, standards organizations, other government agencies, and researchers to achieve these objectives. We urge you 
to join us in our efforts. 



\section{Appendix B}

Following are the images of the VRML worlds that were demonstrated. The images are represented in the same sequence as they appeared during the demonstration. 


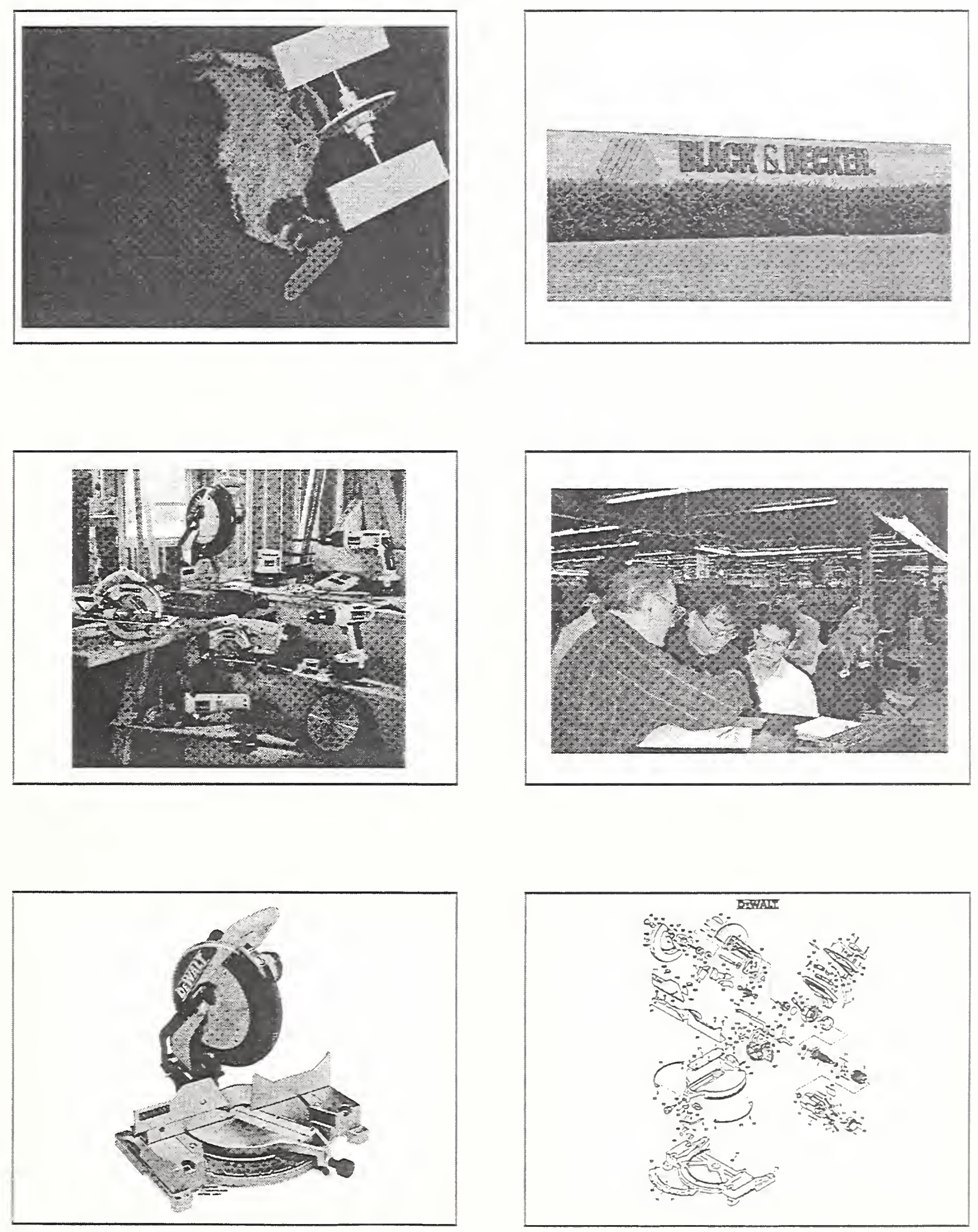

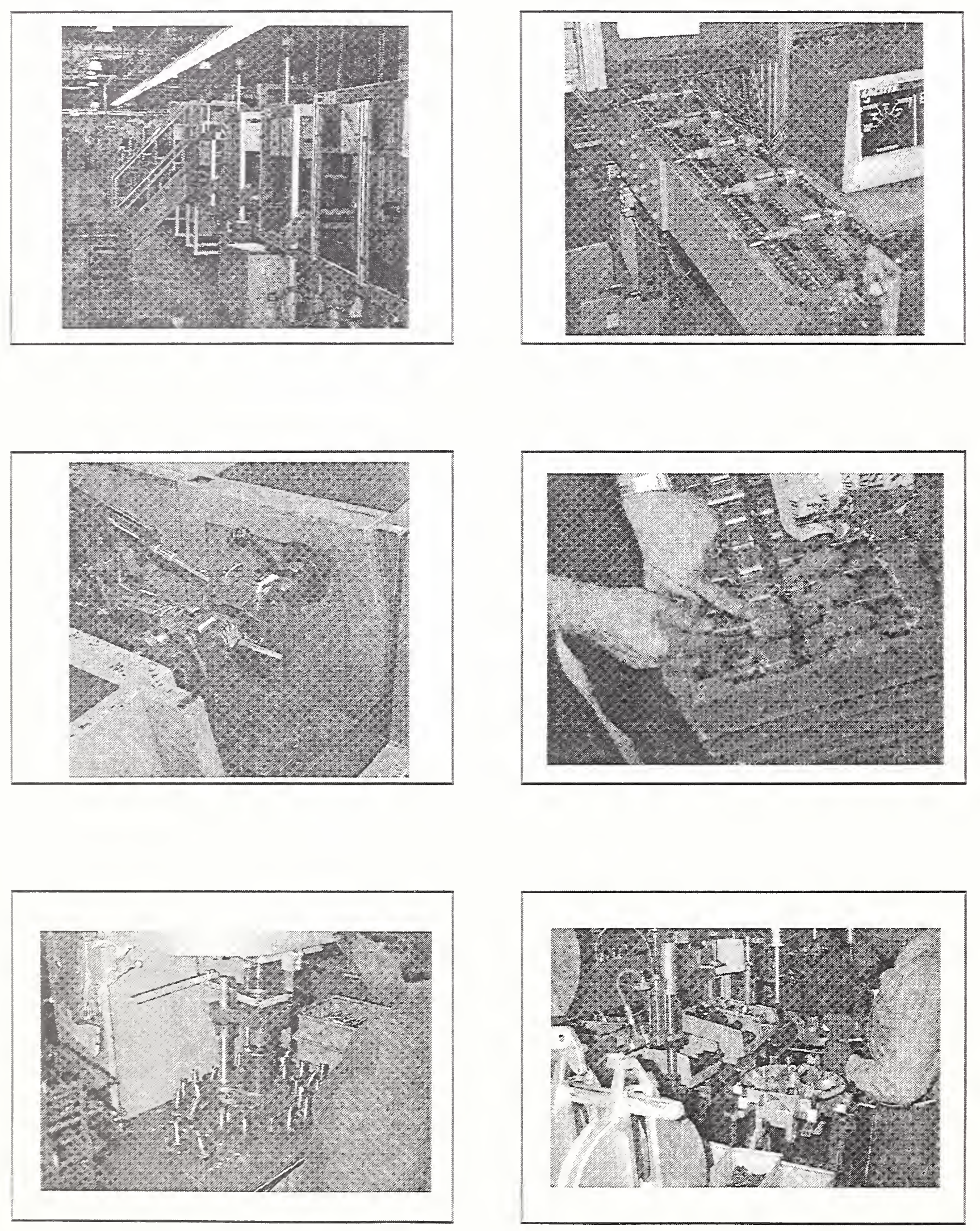

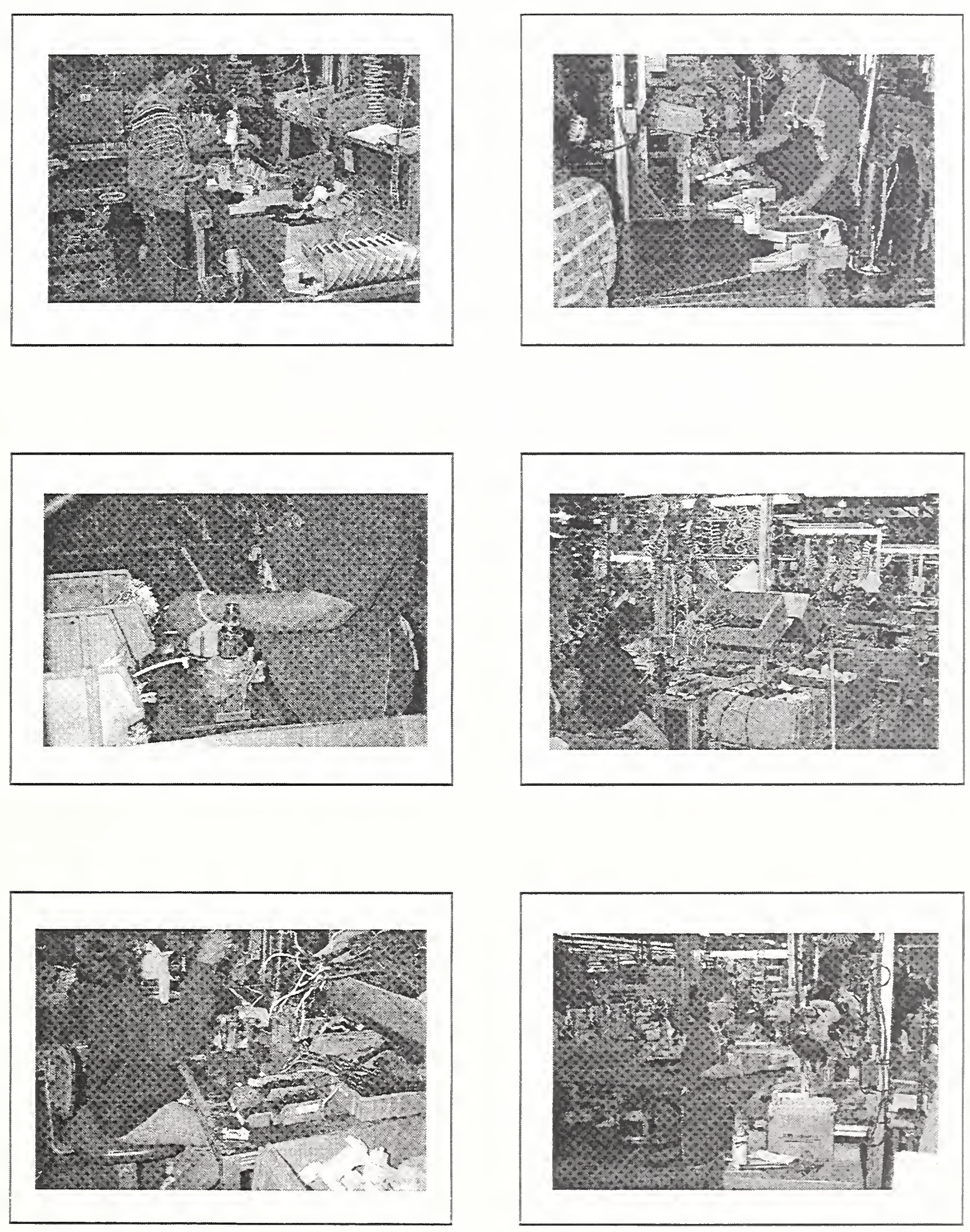

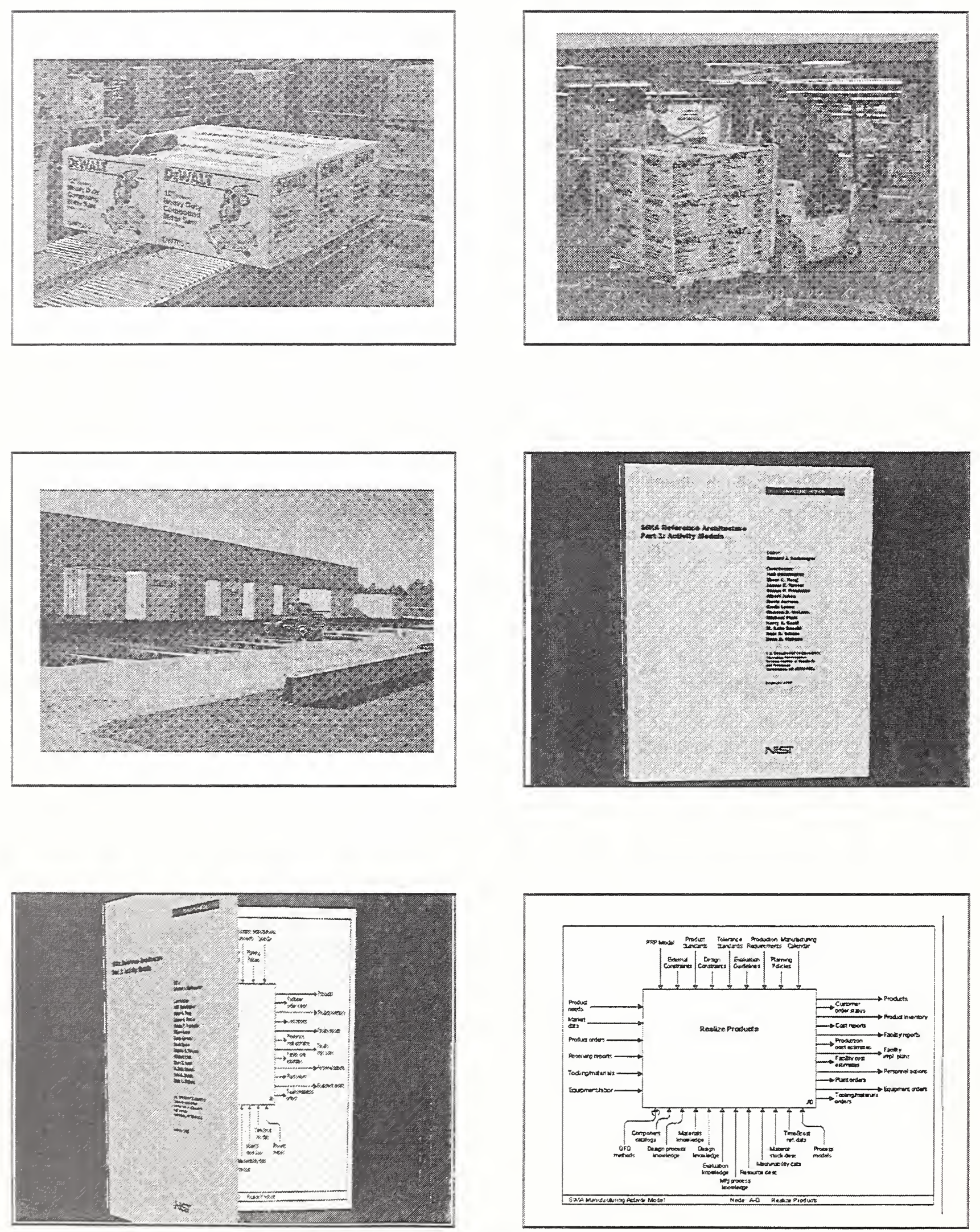



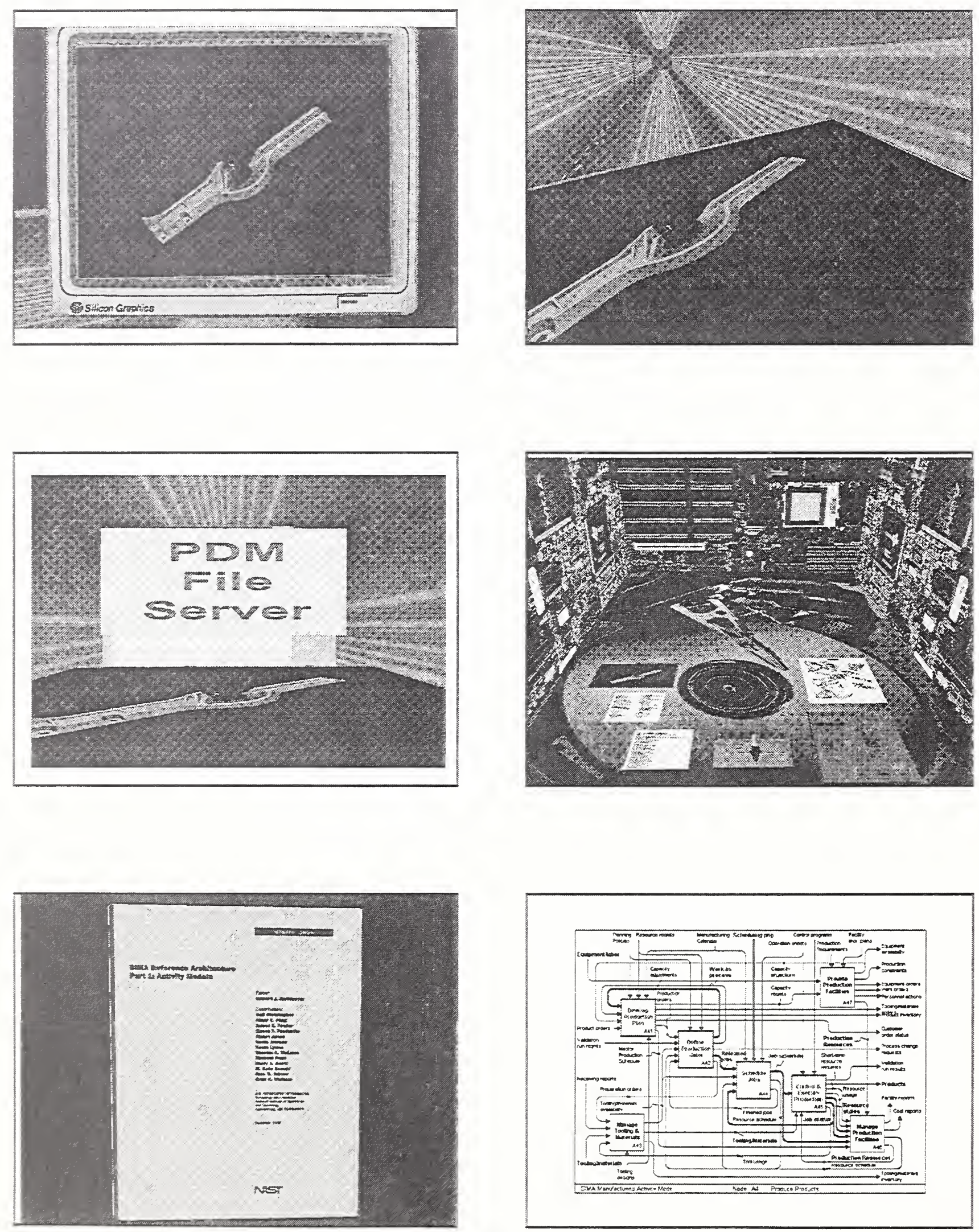

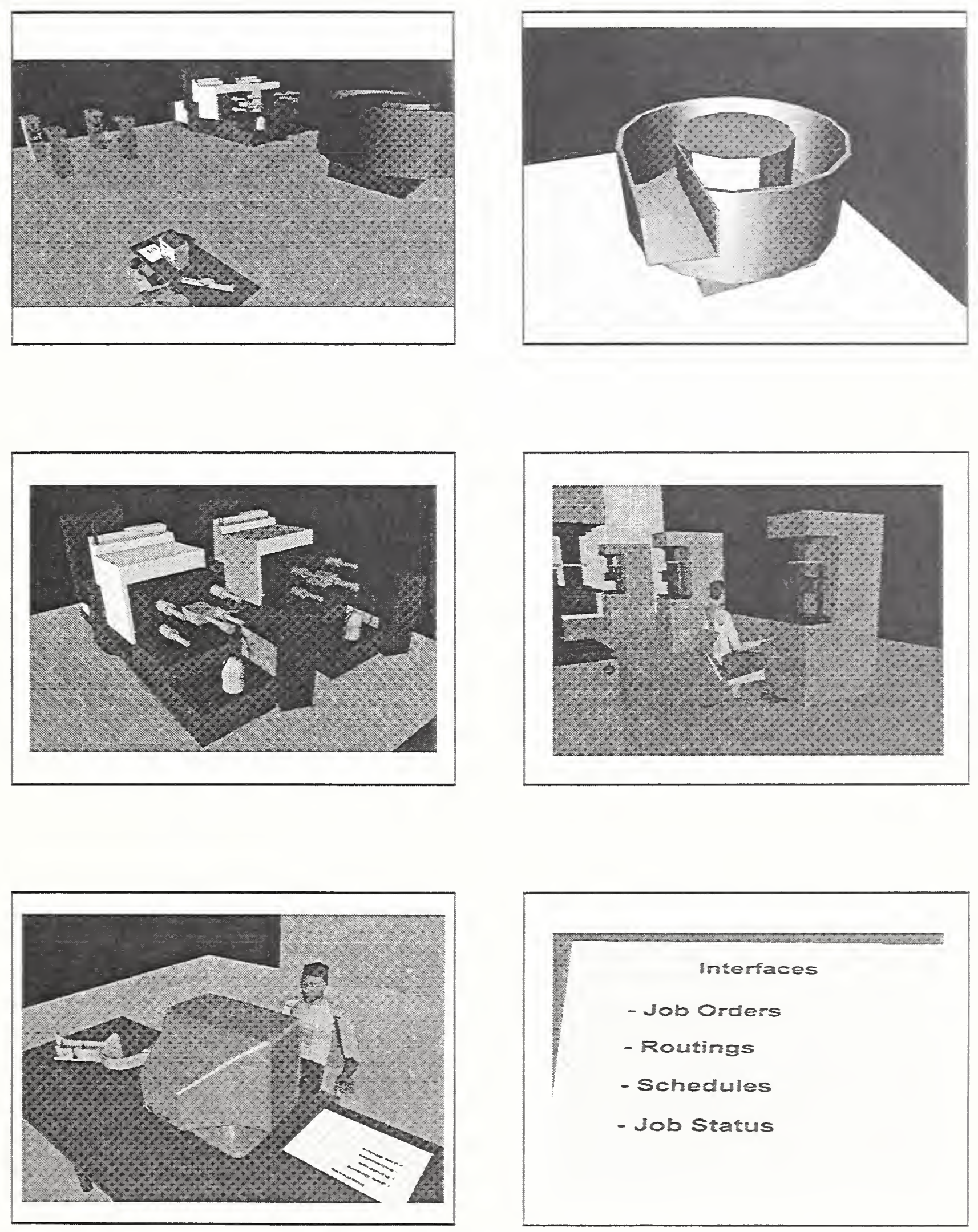

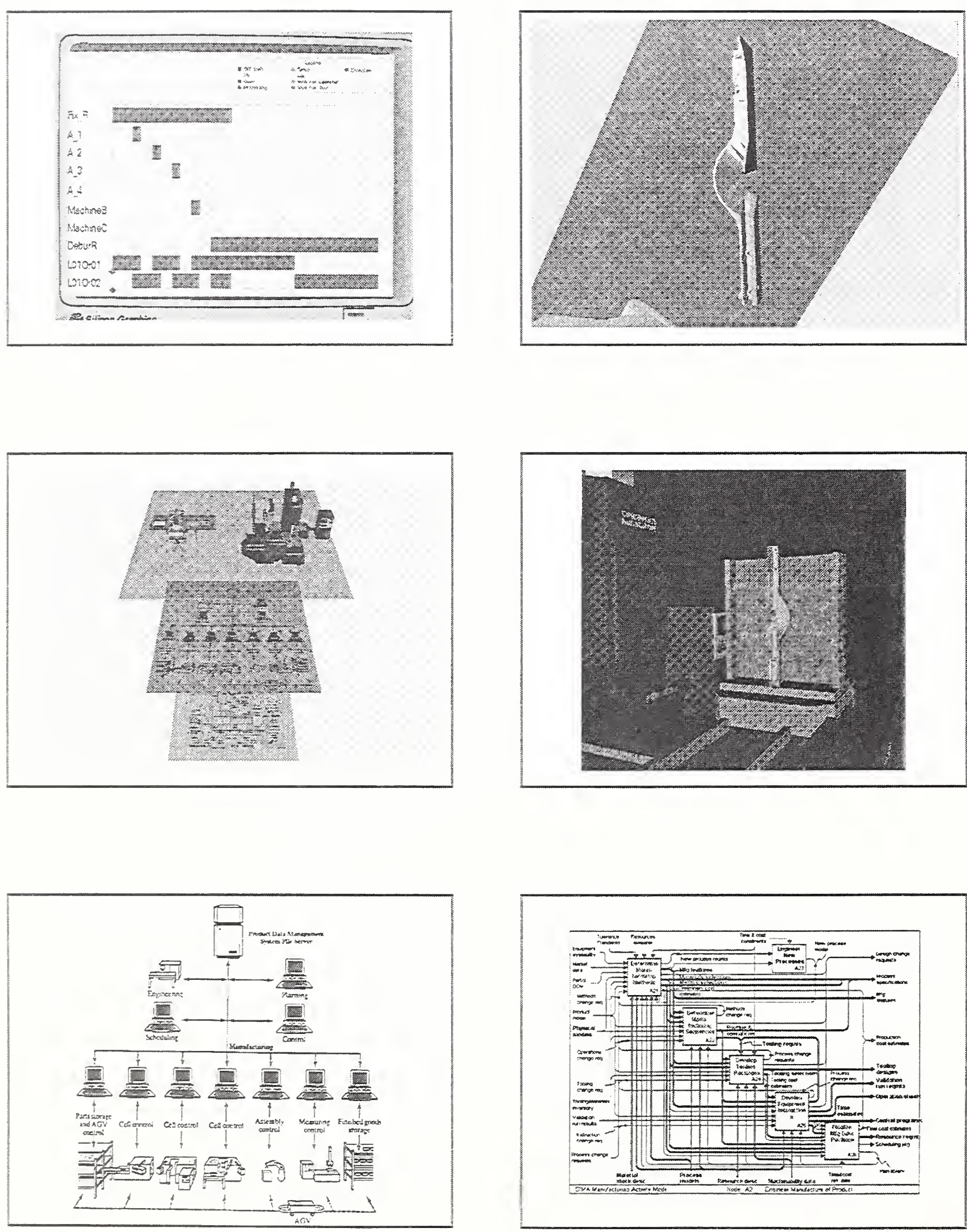


\begin{tabular}{|c|}
\hline Interfaces \\
- Part Designs \\
- Process Plans \\
- NC Programs \\
- Cutting Tool Lists \\
\\
\hline
\end{tabular}
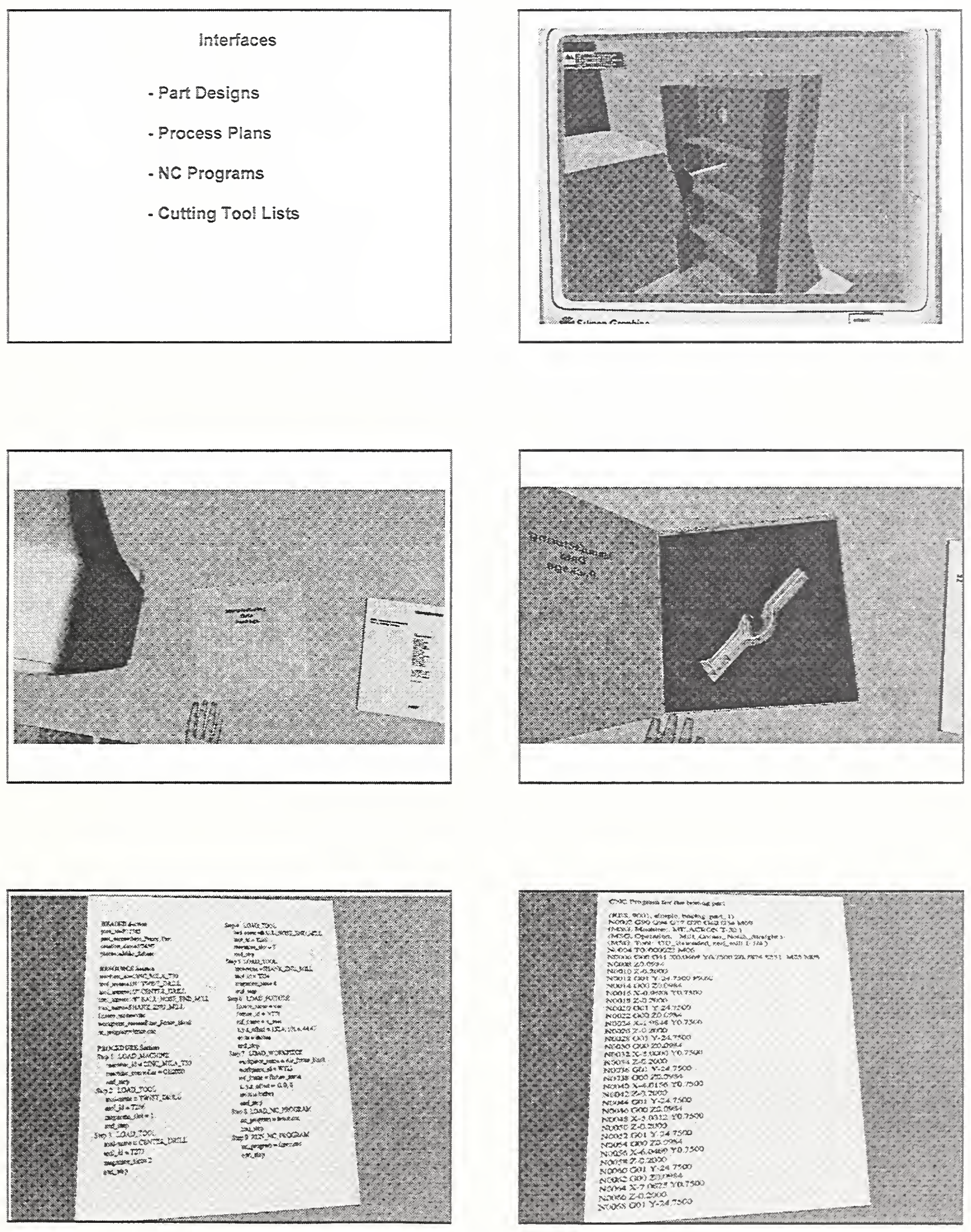

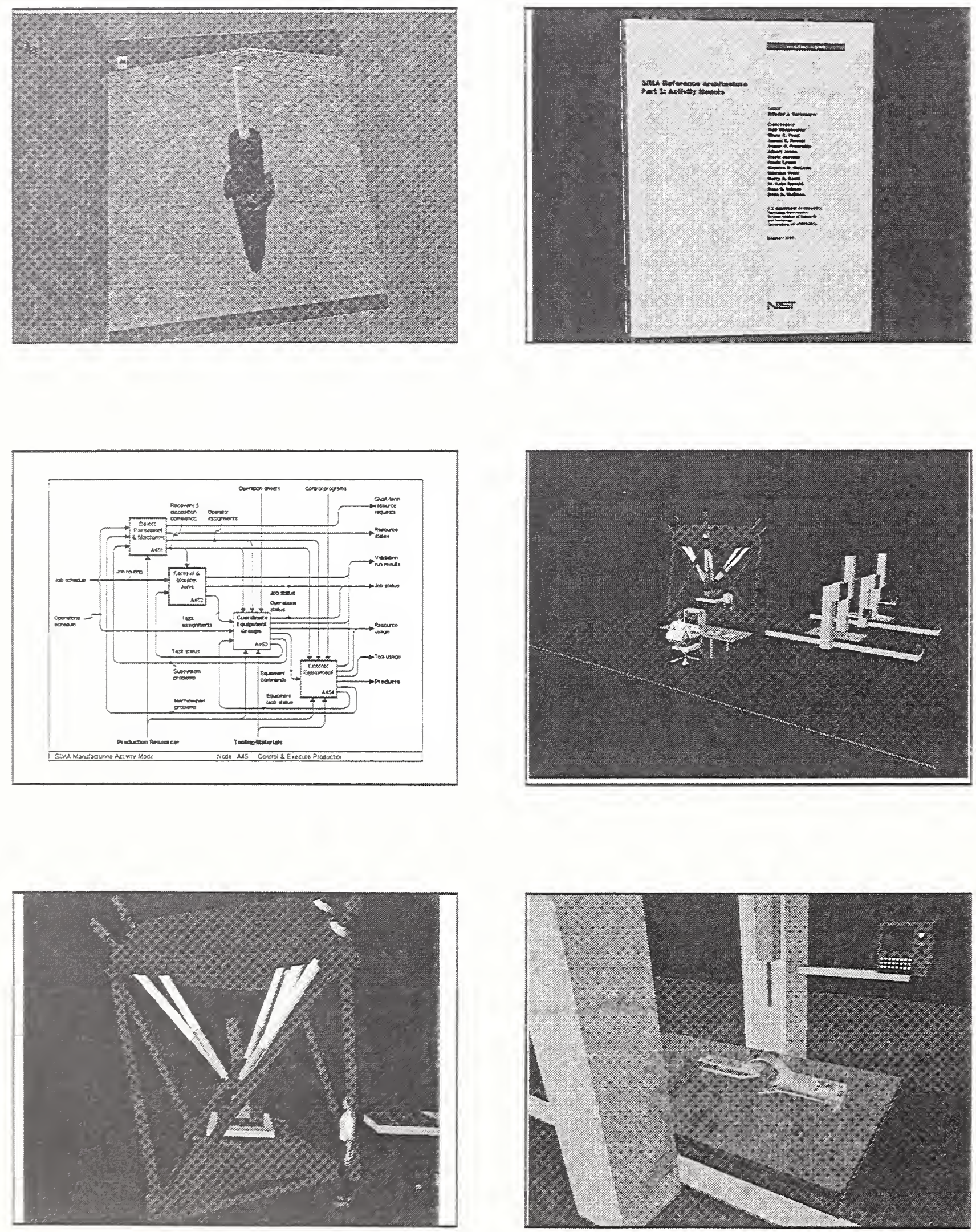


\begin{tabular}{|c|}
\hline Interiaces \\
- PDM Access Protocol \\
- Std. Data Access Interface \\
- Mfg. Execution System \\
Objects \\
- Inspection and Hexapod \\
Work Cell Objects \\
\end{tabular}
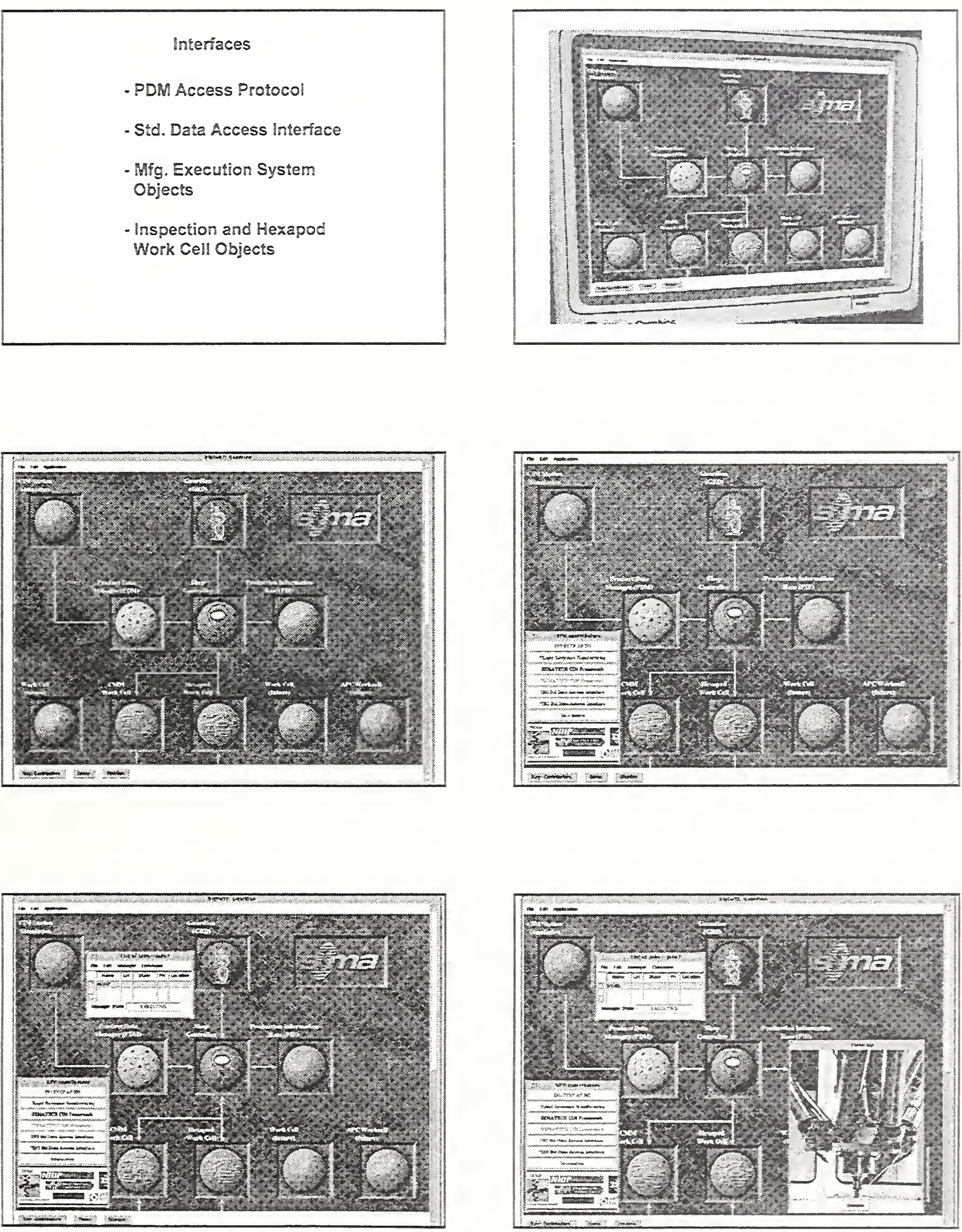

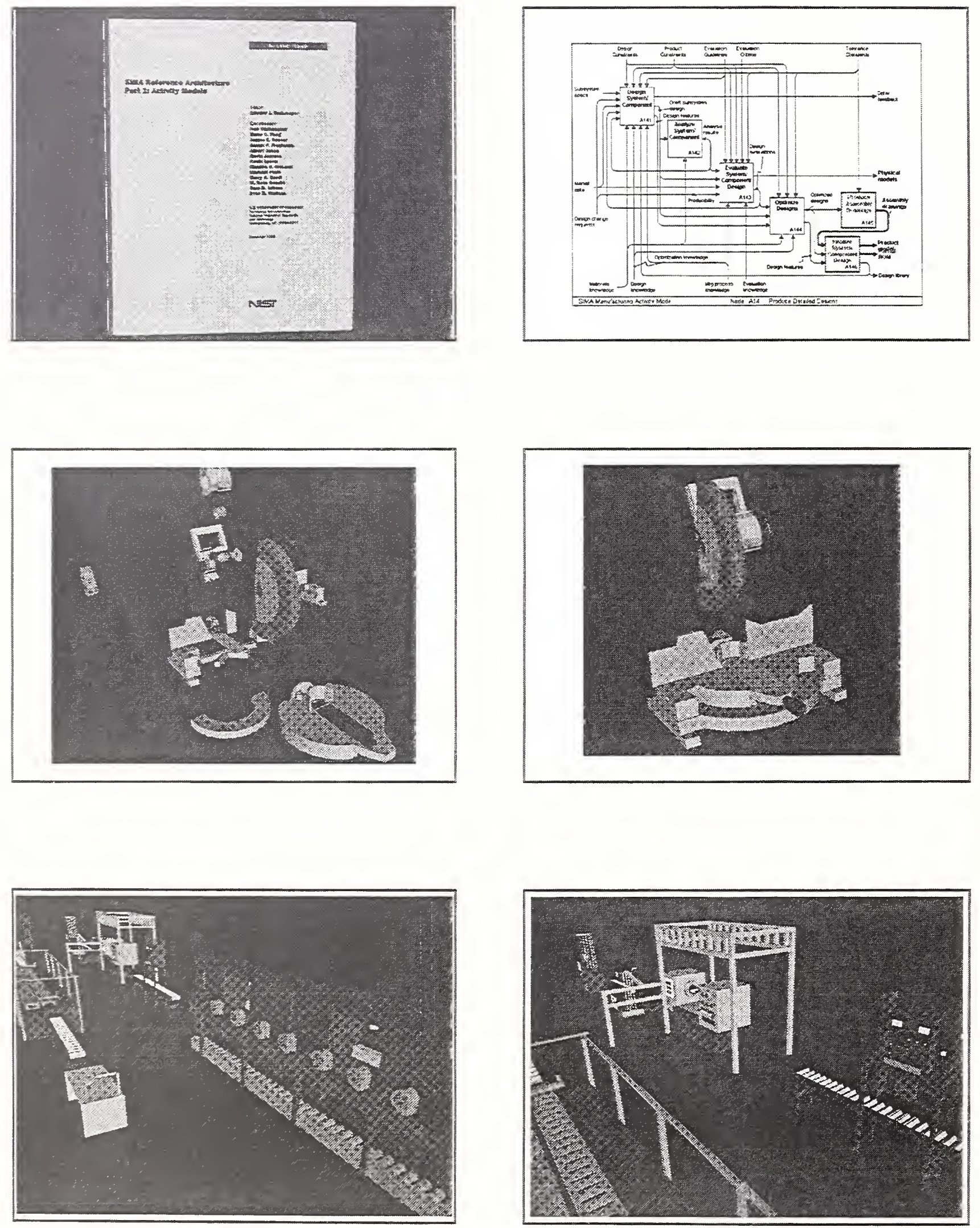

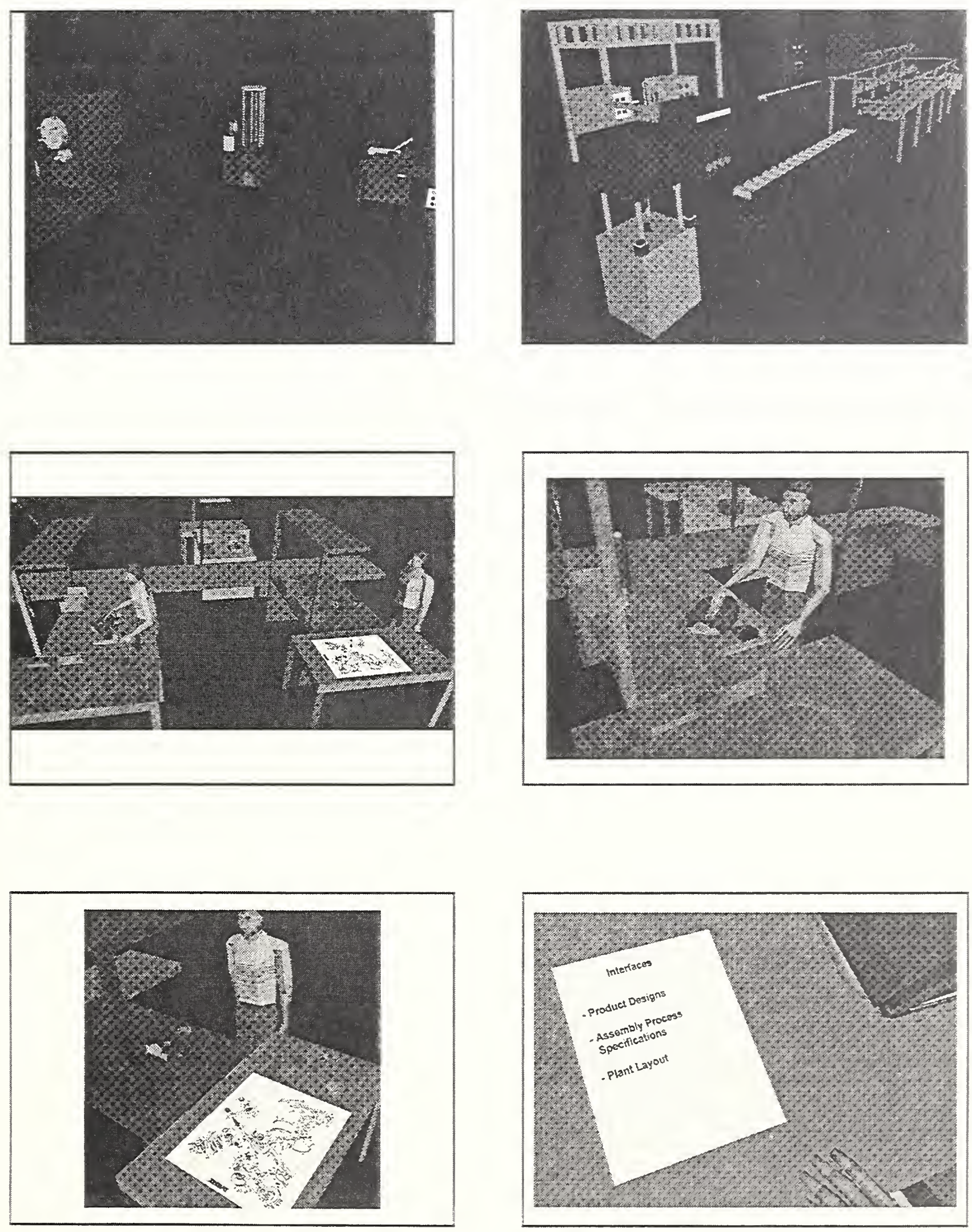

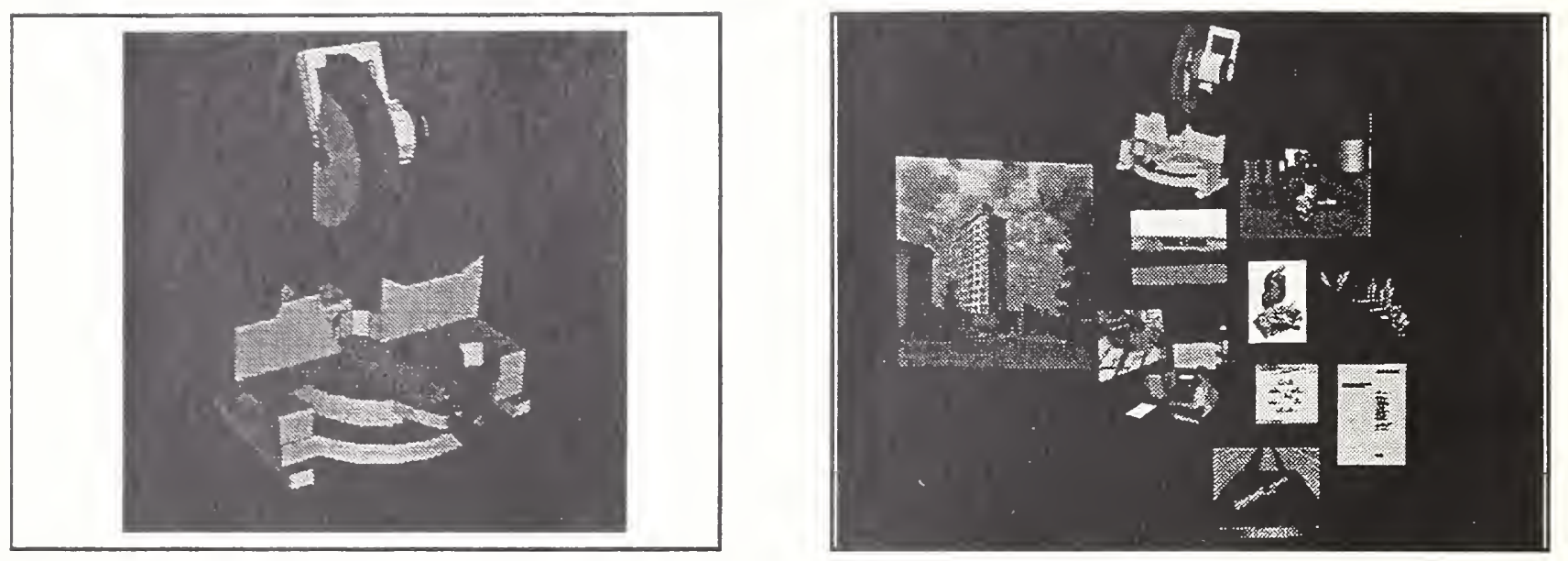

